\title{
Optimal design and planning of glycerol-based biorefinery supply chains under uncertainty
}

\author{
Loureiro da Costa Lira Gargalo, Carina; Carvalho, Ana; Gernaey, Krist V.; Sin, Gürkan
}

Published in:

Industrial \& Engineering Chemistry Research

Link to article, DOI:

10.1021/acs.iecr.7b02882

Publication date:

2017

Document Version

Peer reviewed version

Link back to DTU Orbit

Citation (APA):

Loureiro da Costa Lira Gargalo, C., Carvalho, A., Gernaey, K. V., \& Sin, G. (2017). Optimal design and planning of glycerol-based biorefinery supply chains under uncertainty. Industrial \& Engineering Chemistry Research, 56(41), 11870-11893. https://doi.org/10.1021/acs.iecr.7b02882

\section{General rights}

Copyright and moral rights for the publications made accessible in the public portal are retained by the authors and/or other copyright owners and it is a condition of accessing publications that users recognise and abide by the legal requirements associated with these rights.

- Users may download and print one copy of any publication from the public portal for the purpose of private study or research.

- You may not further distribute the material or use it for any profit-making activity or commercial gain

- You may freely distribute the URL identifying the publication in the public portal 


\title{
Article
}

\section{Optimal design and planning of glycerol-based biorefinery supply chains under uncertainty}

\author{
Carina Lira Gargalo, Ana Carvalho, Krist V. Gernaey, and Gurkan Sin
}

Ind. Eng. Chem. Res., Just Accepted Manuscript • DOI: 10.1021/acs.iecr.7b02882 • Publication Date (Web): 20 Sep 2017

Downloaded from http://pubs.acs.org on September 26, 2017

\section{Just Accepted}

"Just Accepted" manuscripts have been peer-reviewed and accepted for publication. They are posted online prior to technical editing, formatting for publication and author proofing. The American Chemical Society provides "Just Accepted" as a free service to the research community to expedite the dissemination of scientific material as soon as possible after acceptance. "Just Accepted" manuscripts appear in full in PDF format accompanied by an HTML abstract. "Just Accepted" manuscripts have been fully peer reviewed, but should not be considered the official version of record. They are accessible to all readers and citable by the Digital Object Identifier (DOI®). "Just Accepted" is an optional service offered to authors. Therefore, the "Just Accepted" Web site may not include all articles that will be published in the journal. After a manuscript is technically edited and formatted, it will be removed from the "Just Accepted" Web site and published as an ASAP article. Note that technical editing may introduce minor changes to the manuscript text and/or graphics which could affect content, and all legal disclaimers and ethical guidelines that apply to the journal pertain. ACS cannot be held responsible for errors or consequences arising from the use of information contained in these "Just Accepted" manuscripts. 


\title{
Optimal design and planning of glycerol-based biorefinery supply chains under uncertainty
}

\author{
Carina L. Gargalo ${ }^{1}$, Ana Carvalho ${ }^{2}$, Krist V. Gernaey ${ }^{1}$ and Gürkan Sin ${ }^{*}$ \\ ${ }^{1}$ Process and Systems Engineering Center (PROSYS), Department of Chemical and Biochemical Engineering, \\ Technical University of Denmark, Building 229, 2800 Kgs. Lyngby, Denmark \\ ${ }^{2}$ CEG-IST, Instituto Superior Técnico, Universidade de Lisboa, Av. Rovisco Pais,1, 1049-001 Lisboa, \\ Portugal \\ *gsi@,kt.dtu.dk.
}

\begin{abstract}
:
The optimal design and planning of glycerol-based biorefinery supply chains is critical for the development and implementation of this concept in a sustainable manner. To achieve this, a decision-making framework is proposed in this work, to holistically optimize the design and planning of the glycerol-based biorefinery supply chains under uncertainties. This framework presents a multi-layered strategy composed of different steps, and it is strongly based on optimization techniques, detailed economic and environmental assessment, and multi-objective optimization under a stochastic environment. To maximize the business value, the economic objective is measured by the Net Present Value (NPV), whereas the environmental performance is measured by the estimation of a Single Indicator (SI) through the application of LCA methods. As part of the framework, a stochastic multi-period, multi-product and multi-echelon mixed integer linear programming problem is proposed based upon a previous model, GlyThink. In the new formulation, market uncertainties are taken into account at the strategic planning level. The robustness of the supply chain structures is analyzed based on statistical data provided by the implementation of the Monte Carlo method, where a deterministic optimization problem is solved for each scenario. Furthermore, the solution of the stochastic multi-objective optimization model, points to the Pareto set of trade-off solutions obtained when maximizing the NPV and minimizing environmental consequences. Therefore, the proposed framework ultimately leads to the identification of the optimal design and planning decisions for the development of environmentally conscious biorefinery supply chains. The effectiveness of the presented approach is demonstrated through its application to the realistic case study of the glycerol-based biorefinery in Europe, where the results showed that the optimal solution under market uncertainties is obtained by establishing a multiplant supply chain for the glycerol-based integrated biorefinery, built upon two plant site locations (Germany, France) based on the production of succinic acid and lactic acid.
\end{abstract}

Keywords: sustainable supply chain, glycerol, LCA, uncertainty, sustainability 


\section{Introduction}

Drivers such as our deep dependence on fossil fuels availability and price volatility, global concern about climate change and social distress, are steering the economy to be more sustainable and based on a greater use of renewable resources (1). Therefore, the concept of integrated biorefineries has attracted much attention by aspiring at replacing fossil sources, through the conversion of all types of biomass (organic residues, crops, etc.) into a broad plethora of bio-based products, such as fuels, chemicals, power and heat, among others $(1,2)$.

Thus, it seems that an economy based on the innovative and cost-efficient use of bio-resources for the production of both bioproducts and biofuels/bioenergy, is in fact very promising regarding the three pillars of sustainability (3). This leads to an increased interest into biorefineries and highlights the need for a robust bio-based economy. However, to be competitive in the long run, robust systems for the acquisition, production and distribution of these bioproducts must be in place. Therefore, it is critical to analyze and develop a holistic understanding about biorefineries, which entails careful selection of supply chain design and planning, minimizing the threats, from feedstock suppliers, to technologies and product portfolio (4), (5).

A strong challenge is that evolving technologies are accompanied by uncertain performance characteristics, which leads to a significant number of possible options regarding the design, operation and product portfolio offered by biorefineries (6). From these, the most suitable process configuration must be selected, with regards to economics, environmental constraints and overall sustainability $(6,7)$. Given the multiplicity of large (bio)chemical operations and the often-conflicting objectives among the different business divisions, such as planning, manufacturing, distribution and environmental concerns, it is therefore vital to develop a robust framework to capture the synergies and the tradeoffs within bio-based manufacturing. Moreover, in today's ever changing global markets, keeping an efficient and flexible supply chain is paramount for every project/business, and the overall sustainability and reliability of the bio-based supply chains is of primary importance for the establishment of a successful bioeconomy (6). Therefore, inherent uncertainties must not be overlooked. Nevertheless, most of the applications in the bio-based supply chain have to a great extent focused solely on deterministic problems, such as network optimization and plant location problems, by using mixed integer linear programming (MILP) (3,8). However, there are several sources of operational and strategic uncertainties regarding biomass to bioproducts supply chains, which might also differ in their relative importance $(9,10)$. Underestimating the impact of techno-economic uncertainties, can lead to faulty/inferior planning decisions that neither shield the project against threats nor take advantage of the potential opportunities, thus affecting the network's performance and possibly leading to high risk or even unfeasible supply chain designs (11-13). Therefore, it is of great significance to include uncertainties during the planning and design of the biorefinery (8). All in all, there is an urgent need for novel research and 
updated models on the subject of integrated biorefineries, focusing not only on how to evolve towards a biobased economy, but also on how to deal with sustainability concerns and intrinsic uncertainties, keeping an efficient and flexible supply chain so that this industry can compete efficiently with the petro-based industry $(5,14,15)$. Therefore, this work targets at providing an effective decision-making framework, strongly based upon the built-in modeling framework, for the strategic design and planning of biorefinery supply chains under uncertainties. However, being developed for the optimal design and planning of glycerol-based biorefinery supply chains, the proposed framework is flexible and adaptable to other biorefineries similar in nature.

Furthermore, this is the first contribution, to the best of our knowledge, that addresses the optimal design and planning of the realistic supply chain in Europe for the glycerol valorization into value-added chemicals. The design space is built considering cross-country combinations for the optimal location of the plant site facilities, several suppliers, multiple upgrading technologies, crude glycerol acquisition and distribution logistics from the plant site location(s) to the market sinks.

The remainder of the manuscript is organized as follows. In Section 2, the background literature is presented, focusing on (i) how inherent uncertainty on biorefinery supply chains has been dealt with in the past, as well as (ii) on metrics and methods used for the inclusion of the environmental impact assessment. Section 3 introduces and describes in detail the framework proposed in this work for the design and planning of glycerol supply chains. The results and the discussion are presented in Section 4. Lastly, key conclusions are drawn and 'take home' messages are formulated in Section 5.

\section{Literature review}

\subsection{Uncertainty in biomass to biofuels/bioproducts supply chain}

Uncertainties in the biomass to biofuels/bioproducts (BSC) supply chain are significant, coming from all stages, operations and activities (16). As mentioned, disregarding uncertainties in BSC may affect the feasibility and efficiency of the supply chain, potentially leading to infeasible or sub-optimal solutions (8). However, despite the importance of incorporating the treatment of uncertainties into the optimization problem formulation, a great number of approaches devised to date in the topic of sustainable design and planning of biorefinery supply chains are deterministic $(3,8)$. Non-deterministic models have tackled uncertainties in different ways, where, to date, the most used approach is stochastic programing, followed by robust optimization and fuzzy programming. Where, the most studied sources of uncertainty found in nondeterministic BSC optimization literature, include biomass supply, product demand, prices due to seasonal fluctuations and/or economic conditions, and technology evolution, such as technical yields, among others $(3,16)$. A summary of relevant works concerning the explicit incorporation of uncertainties on the design and 
planning of biorefinery supply chain networks is presented in Table 1. It entails mixed integer linear programming (MILP) models developed specifically for the optimal design and planning of biorefinery supply chain networks under uncertainties. As can be observed, all studies listed here were developed for the biomass to biofuel supply chain, mostly focused on the bioethanol production. Furthermore, since product portfolio design is one of the main goals of this work, a more detailed analysis covering the studies that propose multi-product approaches is performed (40\% of the studies reported in Table 1) and introduced based on relevance and in chronological order.

Kim et al. $(2011 \mathrm{a}, \mathrm{b})(17,18)$ proposed a two-stage stochastic optimization problem for the identification of optimal decisions on the supply and facility location, along with production capacity, by maximizing the single-period total profit, under uncertainties on biomass supply, biofuel demand and prices. Further, Gebralssie (2012) (8) proposed a bi-objective stochastic optimization model that enables technology and capacity selection, and production and logistics planning, by minimizing the multi-period total cost and financial risk, under supply and demand uncertainties. Similarly, Kostin et al. (2012)(19) aiming at maximizing the expected performance of the SC under financial risk mitigation, presented a multi-period and multiobjective scenario based optimization problem under demand uncertainty, to decide on the capacity of production plants and storage, along with production rates and product flows. McLean and Li (2013)(20) also suggested a scenario based optimization model, however limited to the identification of supply location and production technology through the maximization of the total profit considering both uncertainties on the biomass supply and product demand. To determine only the optimal planning decisions regarding the biomass supply and amounts of product manufactured, Awudu and Zhang (2013) (21) introduced a singleperiod stochastic programming model maximizing the expected total profit, under uncertainties on product demand and prices. Tong et al. (2013) (22) suggested a multi-period scenario-based stochastic optimization problem to identify the optimal decisions regarding design and operations of the biorefinery to be incorporated into crude refineries, by minimizing the total cost when subjected to price and quantity uncertainties. Also, addressing the minimization of the total annualized costs of incorporating a biorefinery into the crude refineries, Tong et al. (2014a) (22) proposed a multi-period stochastic model to optimize the expectation of the objective function under a number of scenarios associated with biomass availability, fuel demand, crude oil prices, and technology evolution. However, in a further work, Tong et al. (2014b) (23) presented a single-period fractional programming model where the aim was to optimize the unit cost of the downstream design and planning of the same case study, tackling uncertainties on the biomass supply and biofuel demand. However, addressing the effect of the same uncertainties also on the downstream supply chain, Kasivisvanathan et al. (2014) (24) presented a single-period robust programming model that, by minimizing the total cost, led to the optimal decisions regarding technology and capacity selection. 
In a more recent work by Geraili and Romagnoli (2015) (25), a multi-objective stochastic optimization approach is proposed to, under price uncertainty, incorporate the tradeoffs between the cost and the financial risk, leading to the optimal decision regarding technology and capacity selection. In a subsequent study also based on a stochastic optimization model, Geraili et al. (2016) (26) present a decision support tool for the maximization of the NPV in order to optimize the production capacity, and the operating conditions of the plant. This tool includes a simulation based global sensitivity analysis to identify the most critical uncertainties concerning market and operational uncertainties.

Moreover, as observed in Table 1, studies covering both economic and environmental concerns are rather limited. For example, Giarola et al. (2012) (27) presented a MILP model for the optimal upstream strategic and planning decisions of the ethanol supply chain, where both the economic (NPV) and the environmental impact (global warming potential, GWP) of the supply chain are optimized considering carbon trading cost uncertainty. In a similar fashion, Giarola et al. (2013) (28) also proposed a model for the optimal strategic and planning decisions under carbon trading uncertainty of the ethanol supply chain based on the previous work. However, both economic (NPV) and environmental impact (global warming potential, GWP) are optimized considering the user's risk mitigation preferences. More recently, Santibanez-Aguilar et al. (2016) (29) proposed a scenario-based optimization problem to identify the optimal supply allocation under biomass price uncertainty, where the environmental impact is measured through the Eco-indicator 99 method, and the economic performance is determined by the net annual profit.

As observed from the discussion above, the primal objective function used for the design and planning of biorefinery supply chain networks under uncertainties is based on economic metrics. In the works where both objectives are present and tested under uncertainties, the environmental indicator is only given by $\mathrm{CO}_{2}$ emissions. Among these, the most frequently used are single-period optimization problems, maximizing the total profit or minimizing the total costs. Moreover, studies covering the full supply chain including design and planning decisions all the way from the feedstock supplier, technology and capacity selection, and delivery to the final markets, are limited. Therefore, our contribution arises from these identified research gaps, by providing a holistic multi-level decision-making framework, strongly based on operation research techniques: single- and multi-objective deterministic and stochastic optimization, simulation (Monte Carlo). The proposed integrated framework ultimately leads to the identification of the optimal design and planning decisions for the development of environmentally conscious biorefinery supply chains, where the consequences of external economic uncertainties on the environmental objective function are analyzed and the trade-offs identified.

\subsection{Environmental impact}


Increasing awareness of environmental concerns has been witnessed in a recent past, especially motivated by governmental regulations. Therefore, crescent effort has been made on the incorporation of environmental impact assessment, alongside with typical economic criteria. In order to do so, Life-Cycle Assessment (LCA) has been described as the most scientifically reliable method currently available for studying and evaluating the environmental impacts of a certain product or process (30). This is further enforced by the fact that the European Commission stated in the Sustainable Development Strategy that it is a significant goal to develop and standardize LCA methodologies $(31,32)$. Thus, LCA has become the main tool to analyze environmental consequences related to a product, process or activity.

A standard LCA method, as recommended by (33), begins by establishing the boundaries of analysis of a given good or service (step 1). This step is a guide that assures that the LCA is performed in a consistent manner, where the most important decisions of the analysis are defined in detail, especially regarding the definition of the system boundaries. The life cycle inventory is performed in Step 2, which deals with the environmental inputs and outputs linked to a product or service. This is achieved by collecting all mass and energy requirements, as well as emissions and wastes.

Life cycle impact assessment is the step 3 of the LCA. This step is divided into 4 sub steps: (i) classification: all components are separated into groups according to the burden they have on the environment; (ii) characterization: the components are converted into environmental categories of impact by using component and category specific characterization factors; (iii) normalization: the estimated impact is compared to a reference value; and, (iv) weighting: different values are given to the impacts according to user preferences in order to generate a single score. To this end, a specific life cycle impact assessment method (LCIA method) is selected. Several different LCA methods are available and continuously being developed. These use different models in the characterization step, different normalization assumptions and/or different weighting factors (34). Despite the great benefits of coupling optimization and LCA, works on this topic are still relatively scarce. Even less studies are found that include the environmental modelling through LCA in the supply chain optimization field. Frota Neto et al. (2008) (35) proposed a framework for the design and analysis of sustainable logistic networks, assessing the ecological impact through the environment index, in the pulp and paper industry as example. Guillen-Gosalbez and Grossmann (2009) (36) addressed the design of sustainable chemical supply chains with uncertainty in the life cycle inventory, by using the Eco-indicator 99 LCIA method. Eco-indicator 99 was the selected methodology. Duque et al. (2010) (37) proposed a supply chain model to optimize the decisions regarding production and transportation routes, where the environmental impact is also quantified by using Eco-indicator 99. Likewise, Pinto-Varela et al. (2011) (38) used Ecoindicator 99 to account for environmental concerns when optimizing the design and planning of supply chains. To particular interest of this work, some examples are given in the field of biorefineries that include environmental metrics. Zamboni et al. (2009) (39) developed a spatially-explicit MILP model for the design of 
respectively first and hybrid generation ethanol SCs under economic and environmental performance (GHG emissions) optimization. Mele et al. (2011) (40) and Santibanez-Aguilar et al. (2011) (41) developed a mixedinteger linear program optimizing the economic and environmental performances of bioethanol supply chains using Eco-indicator 99, as well as Global Warming Potential. Similarly, Giarola et al. (2012a) (27) and Giarola et al. (2012b) (28) proposed a spatially-explicit MILP model for the design of respectively first and hybrid generation ethanol SCs under economic and environmental performance (GHG emissions) optimization, under deterministic and uncertainty conditions, respectively. Bernardi et al. (2012) (42) proposed a multiobjective MILP addressing hybrid corn grain and stover supply chains to ethanol production, where the environmental burdens were included through the estimation of the carbon and water footprints. Likewise, You et al. (2012) (43) suggested an approach towards the sustainable design of biorefinery supply chains by including the GHG emission as the environmental objective. More recently, as mentioned in the previous section, Santibanez-Aguilar et al. (2016) (29) proposed a scenario-based optimization problem optimizing the supply allocation under biomass price uncertainty, where the environmental impact is measured through the Eco-indicator 99 method. Lastly, d'Amore and Bezzo (2016) (44) proposed a multi-objective MILP model where the environmental objective is represented in terms of GHG emissions, as well as the analysis of the impact on emissions caused by indirect Land Use Change effects.

As observed, despite the fact that several methods are available for the LCA, which have been applied to different topics and research areas, it is difficult to ascertain which is the best method to follow. However, according to the European Commission report (45), ReCiPe is the most developed method currently available. It is based upon the Eco-indicator 99 combined with CML 2002, and it is described in detail in Goedkoop et al. (2009) (46). Therefore, due to this rationale, the ReCiPe method has been chosen to assess the environmental

impact

in

this

work. 
Table 1: List of publications: MILP problems for the design and planning of biorefinery networks and supply chains, under uncertainties.

\begin{tabular}{|c|c|c|c|c|c|c|c|c|c|c|c|}
\hline \multirow{2}{*}{ references } & \multirow{2}{*}{$\begin{array}{l}\text { Supply } \\
\text { allocation }\end{array}$} & \multirow{2}{*}{$\begin{array}{c}\text { facility } \\
\text { location }\end{array}$} & \multirow{2}{*}{$\begin{array}{l}\text { technology } \\
\text { selection }\end{array}$} & \multirow{2}{*}{$\begin{array}{l}\text { technology } \\
\text { capacity }\end{array}$} & \multirow{2}{*}{$\begin{array}{l}\text { multi- } \\
\text { product }\end{array}$} & \multirow{2}{*}{ products } & \multirow{2}{*}{$\begin{array}{l}\text { multi- } \\
\text { period }\end{array}$} & \multicolumn{2}{|c|}{ Objective functions } & \multirow{2}{*}{ Types of uncertainty } & \multirow{2}{*}{$\begin{array}{c}\text { Region } \\
\text { of the } \\
\text { case } \\
\text { study }\end{array}$} \\
\hline & & & & & & & & Economic & Environmental & & \\
\hline $\begin{array}{l}\text { Dal Mas et al. } \\
(2010)(47)\end{array}$ & - & $\mathrm{x}$ & - & $\mathrm{x}$ & - & biofuel & $\mathrm{x}$ & $\begin{array}{l}\text { Max total profit } \\
+ \text { min risk } \\
\text { investment }\end{array}$ & - & Biofuel price & Italy \\
\hline $\begin{array}{l}\text { Dal Mas et al. } \\
(2011)(48)\end{array}$ & $\mathrm{x}$ & $\mathrm{x}$ & - & $\mathrm{x}$ & - & biofuel & $\mathrm{x}$ & Max NPV & - & Biomass price & Italy \\
\hline $\begin{array}{l}\text { Kim et al. (2011a) } \\
(18)\end{array}$ & $\mathrm{x}$ & $\mathrm{x}$ & - & $\mathrm{x}$ & $\mathrm{x}$ & Gasoline, diesel & - & Max total profit & - & $\begin{array}{l}\text { Supply, market demands, } \\
\text { market prices, processing } \\
\text { technologies }\end{array}$ & USA \\
\hline $\begin{array}{l}\text { Kim et al. (2011b) } \\
(17)\end{array}$ & - & - & - & $\mathrm{x}$ & $\mathrm{x}$ & Gasoline, diesel & - & Max total profit & - & $\begin{array}{l}\text { Biomass supply, biofuel } \\
\text { demand, price }\end{array}$ & USA \\
\hline $\begin{array}{l}\text { Kostin et al. (2012) } \\
\text { (19) }\end{array}$ & $\mathrm{x}$ & - & $\mathrm{x}$ & $\mathrm{x}$ & $\mathrm{x}$ & Sugar, bioethanol & $\mathrm{x}$ & Max NPV & - & Biofuel demand & Argentina \\
\hline $\begin{array}{l}\text { Gebralssie (2012) } \\
(8)\end{array}$ & - & $\mathrm{x}$ & $\mathrm{x}$ & $\mathrm{x}$ & $\mathrm{x}$ & $\begin{array}{l}\text { Gasoline, diesel, } \\
\text { jet fuel }\end{array}$ & $\mathrm{x}$ & $\begin{array}{l}\text { Min total cost }+ \\
\text { min risk }\end{array}$ & - & Supply, demand & USA \\
\hline $\begin{array}{l}\text { McLean and Li } \\
(2013)(20)\end{array}$ & $\mathrm{x}$ & - & $\mathrm{x}$ & - & $\mathrm{x}$ & $\begin{array}{l}\text { Bioethanol, heat, } \\
\text { power }\end{array}$ & $\mathrm{x}$ & Max total profit & - & $\begin{array}{l}\text { Biomass supply, yield of } \\
\text { crops, upper and lower limits } \\
\text { for electricity }\end{array}$ & $\begin{array}{l}\text { Central } \\
\text { Europe }\end{array}$ \\
\hline $\begin{array}{l}\text { Giarola et al. } \\
(2012)(27)\end{array}$ & $\mathrm{x}$ & $\mathrm{x}$ & $\mathrm{x}$ & $\mathrm{x}$ & $\mathrm{x}$ & $\begin{array}{l}\text { Bioethanol, } \\
\text { DDGS, power }\end{array}$ & $\mathrm{x}$ & Max NPV & Min GWP & $\begin{array}{c}\text { Carbon trading cost } \\
\text { uncertainty, biomass cost }\end{array}$ & Italy \\
\hline $\begin{array}{l}\text { Giarola et al. } \\
(2012)(28)\end{array}$ & $\mathrm{x}$ & $\mathrm{x}$ & $\mathrm{x}$ & $\mathrm{x}$ & $\mathrm{x}$ & $\begin{array}{c}\text { Bioethanol, } \\
\text { DDGS, power }\end{array}$ & $\mathrm{x}$ & Max NPV & Min GWP & $\begin{array}{l}\text { Carbon trading cost volatility } \\
\text { according to user's risk } \\
\text { mitigation preferences, } \\
\text { biomass cost }\end{array}$ & Italy \\
\hline $\begin{array}{l}\text { Chen and Fan } \\
(2012)(49)\end{array}$ & - & $\mathrm{x}$ & - & $\mathrm{x}$ & - & biofuel & - & Min total cost & - & $\begin{array}{l}\text { Biomass supply, biofuel } \\
\text { demand }\end{array}$ & USA \\
\hline $\begin{array}{l}\text { Walther et al. } \\
(2012)(50)\end{array}$ & $\mathrm{x}$ & $\mathrm{x}$ & $\mathrm{x}$ & $\mathrm{x}$ & - & biofuel & $\mathrm{x}$ & Max NPV & - & $\begin{array}{l}\text { Biomass production, } \\
\text { investment cost, biofuel } \\
\text { demand }\end{array}$ & Germany \\
\hline $\begin{array}{l}\text { Awudu and Zhang } \\
\text { (2013) (51) }\end{array}$ & $\mathrm{x}$ & $\mathrm{x}$ & $\mathrm{x}$ & - & $\mathrm{x}$ & $\begin{array}{l}\text { Ethanol, corn oil, } \\
\text { DDGS }\end{array}$ & - & Max profit & - & Product price, demand & - \\
\hline $\begin{array}{l}\text { Osmani and Zhang } \\
(2013)(52)\end{array}$ & $\mathrm{x}$ & $\mathrm{x}$ & - & - & - & biofuel & - & Min total cost & - & $\begin{array}{l}\text { Biomass yield, biomass price, } \\
\text { bioethanol price, rainfall level }\end{array}$ & USA \\
\hline $\begin{array}{l}\text { Foo et al. (2013) } \\
(53)\end{array}$ & - & $\mathrm{x}$ & - & - & - & biofuel & - & - & $\begin{array}{l}\text { Min total } \\
\text { carbon } \\
\text { footprint }\end{array}$ & Biomass supply & Malaysia \\
\hline $\begin{array}{l}\text { Tong et al. (2013) } \\
\text { (22) }\end{array}$ & $\mathrm{x}$ & $\mathrm{x}$ & $\mathrm{x}$ & $\mathrm{x}$ & $\mathrm{x}$ & Gasoline, diesel & $\mathrm{x}$ & Min total costs & - & $\begin{array}{l}\text { Biomass supply, crude oil } \\
\text { prices, technology evolution }\end{array}$ & USA \\
\hline $\begin{array}{l}\text { Tong et al. (2014a) } \\
(23)\end{array}$ & $\mathrm{x}$ & $\mathrm{x}$ & $\mathrm{x}$ & $\mathrm{x}$ & $\mathrm{x}$ & $\begin{array}{l}\text { Gasoline, diesel, } \\
\text { jet fuel }\end{array}$ & $\mathrm{x}$ & $\begin{array}{l}\text { Min the unit } \\
\text { cost }\end{array}$ & - & $\begin{array}{l}\text { Biomass supply, product } \\
\text { demand }\end{array}$ & USA \\
\hline $\begin{array}{l}\text { Tong et al. (2014b) } \\
\text { (54) }\end{array}$ & $\mathrm{x}$ & $\mathrm{x}$ & $\mathrm{x}$ & $\mathrm{x}$ & $\mathrm{x}$ & $\begin{array}{l}\text { Gasoline, diesel, } \\
\text { jet fuel }\end{array}$ & - & $\begin{array}{l}\text { Min the unit } \\
\text { cost }\end{array}$ & - & Biomass supply, demand & USA \\
\hline $\begin{array}{l}\text { Kasivisvanathan et } \\
\text { al. (2014) (24) }\end{array}$ & - & - & $\mathrm{x}$ & $\mathrm{x}$ & $\mathrm{x}$ & $\begin{array}{l}\text { Biochar, gasoline, } \\
\text { bio-oil, ethanol, } \\
\text { animal feed }\end{array}$ & - & Min total cost & - & Biomass supply, demand & - \\
\hline $\mathrm{Li}$ and $\mathrm{Hu}$ (2014) & $\mathrm{x}$ & $\mathrm{x}$ & - & $\mathrm{x}$ & - & biofuel & - & Max total profit & - & Biomass supply, technology & USA \\
\hline
\end{tabular}




\begin{tabular}{|c|c|c|c|c|c|c|c|c|c|c|c|}
\hline$(55)$ & & & & & & & & & & advancement, biofuel demand & \\
\hline $\begin{array}{l}\text { Azadeh et al. } \\
(2014)(56)\end{array}$ & $\mathrm{x}$ & $\mathrm{x}$ & $\mathrm{x}$ & $\mathrm{x}$ & - & biofuel & $\mathrm{x}$ & Max total profit & - & Supply, demand & - \\
\hline $\begin{array}{lr}\text { Geraili } & \text { and } \\
\text { Romagnoli } & (2015) \\
(25) & \end{array}$ & - & - & $\mathrm{x}$ & $\mathrm{x}$ & $\mathrm{x}$ & $\begin{array}{l}\text { Ethanol, succinic } \\
\text { acid, electricity }\end{array}$ & $\mathrm{x}$ & $\begin{array}{l}\text { Max NPV + } \\
\text { min risk }\end{array}$ & - & Biannual crude oil price & - \\
\hline $\begin{array}{l}\text { Gonela et al. } \\
(2015 a)(57)\end{array}$ & $\mathrm{x}$ & $\mathrm{x}$ & - & $\mathrm{x}$ & $\mathrm{x}$ & bioethanol & $\mathrm{x}$ & Max total profit & - & $\begin{array}{l}\text { Product price, product } \\
\text { demand, yield of } 1 \text { st and } 2 \text { nd } \\
\text { generation biomass }\end{array}$ & USA \\
\hline $\begin{array}{l}\text { Gonela et al. } \\
(2015 \mathrm{a})(58)\end{array}$ & $\mathrm{x}$ & $\mathrm{x}$ & - & $\mathrm{x}$ & $\mathrm{x}$ & bioethanol & $\mathrm{x}$ & Max total profit & - & $\begin{array}{l}\text { Product price, product } \\
\text { demand, biomass yield }\end{array}$ & USA \\
\hline $\begin{array}{l}\text { Sharifazedah et al. } \\
\text { (2015) (59) }\end{array}$ & $\mathrm{x}$ & - & - & - & - & biofuel & $\mathrm{x}$ & Max NPV & - & $\begin{array}{l}\text { Biomass supply, biofuel } \\
\text { demand }\end{array}$ & UK \\
\hline $\begin{array}{l}\text { Geraili et al. (2016) } \\
\text { (26) }\end{array}$ & - & - & $x$ & $\mathrm{x}$ & $\mathrm{x}$ & $\begin{array}{l}\text { Ethanol, succinic } \\
\text { acid, electricity, } \\
\text { treated water, } \\
\text { steam }\end{array}$ & $\mathrm{x}$ & Max NPV & - & $\begin{array}{l}\text { Market and operational } \\
\text { uncertainties }\end{array}$ & - \\
\hline $\begin{array}{l}\text { Santibanez-Aguilar } \\
\text { et al. (2016) (29) }\end{array}$ & $\mathrm{x}$ & - & - & - & & $\begin{array}{c}\text { Bioethanol, } \\
\text { biodiesel }\end{array}$ & $\mathrm{x}$ & Max total profit & $\begin{array}{l}\text { Min Eco- } \\
\text { indicator } 99\end{array}$ & Biomass price & Mexico \\
\hline $\begin{array}{l}\text { Azadeh and Arani } \\
(2016)(60)\end{array}$ & $\mathrm{x}$ & $\mathrm{x}$ & $\mathrm{x}$ & - & - & biofuel & $\mathrm{x}$ & Max total profit & - & $\begin{array}{l}\text { Biomass supply, biofuel } \\
\text { demand }\end{array}$ & - \\
\hline $\begin{array}{l}\text { Mohsemi et al. } \\
(2016)(61)\end{array}$ & $\mathrm{x}$ & $\mathrm{x}$ & - & $\mathrm{x}$ & - & biodiesel & $\mathrm{x}$ & Min total cost & - & $\begin{array}{l}\text { Supply, cost parameters, } \\
\text { technical factors, biodiesel } \\
\text { demand }\end{array}$ & Iran \\
\hline $\begin{array}{l}\text { Balaman and Selim } \\
\text { (2016) (62) }\end{array}$ & $\mathrm{x}$ & $\mathrm{x}$ & $\mathrm{x}$ & $\mathrm{x}$ & - & - & $\mathrm{x}$ & $\begin{array}{l}\text { Min total cost }+ \\
\text { min total service } \\
\text { level }\end{array}$ & - & $\begin{array}{l}\text { Unit cost of thermal energy } \\
\text { storage, upper limit storage of } \\
\text { thermal energy, thermal } \\
\text { energy demand per household }\end{array}$ & Turkey \\
\hline $\begin{array}{lll}\text { Yue } & \text { and } & \text { You } \\
(2016)(9) & \end{array}$ & $\mathrm{x}$ & $\mathrm{x}$ & - & $\mathrm{x}$ & $\mathrm{x}$ & ethanol & $\mathrm{x}$ & Min total cost & . & $\begin{array}{l}\text { Conversion efficiency, yield of } \\
\text { biomass, biomass supply, } \\
\text { ethanol demand }\end{array}$ & $\begin{array}{l}\text { Illinois, } \\
\text { USA }\end{array}$ \\
\hline
\end{tabular}




\section{Framework for decision-making under uncertainty}

The main goal of this work is to identify and critically analyze the optimal integrated glycerol-based biorefinery supply chain for the valorization of glycerol into high value-added products. Therefore, in this section, the integrated framework for the design, planning and analysis of glycerol-based biorefinery supply chains under uncertainties is proposed and presented in Figure 1.

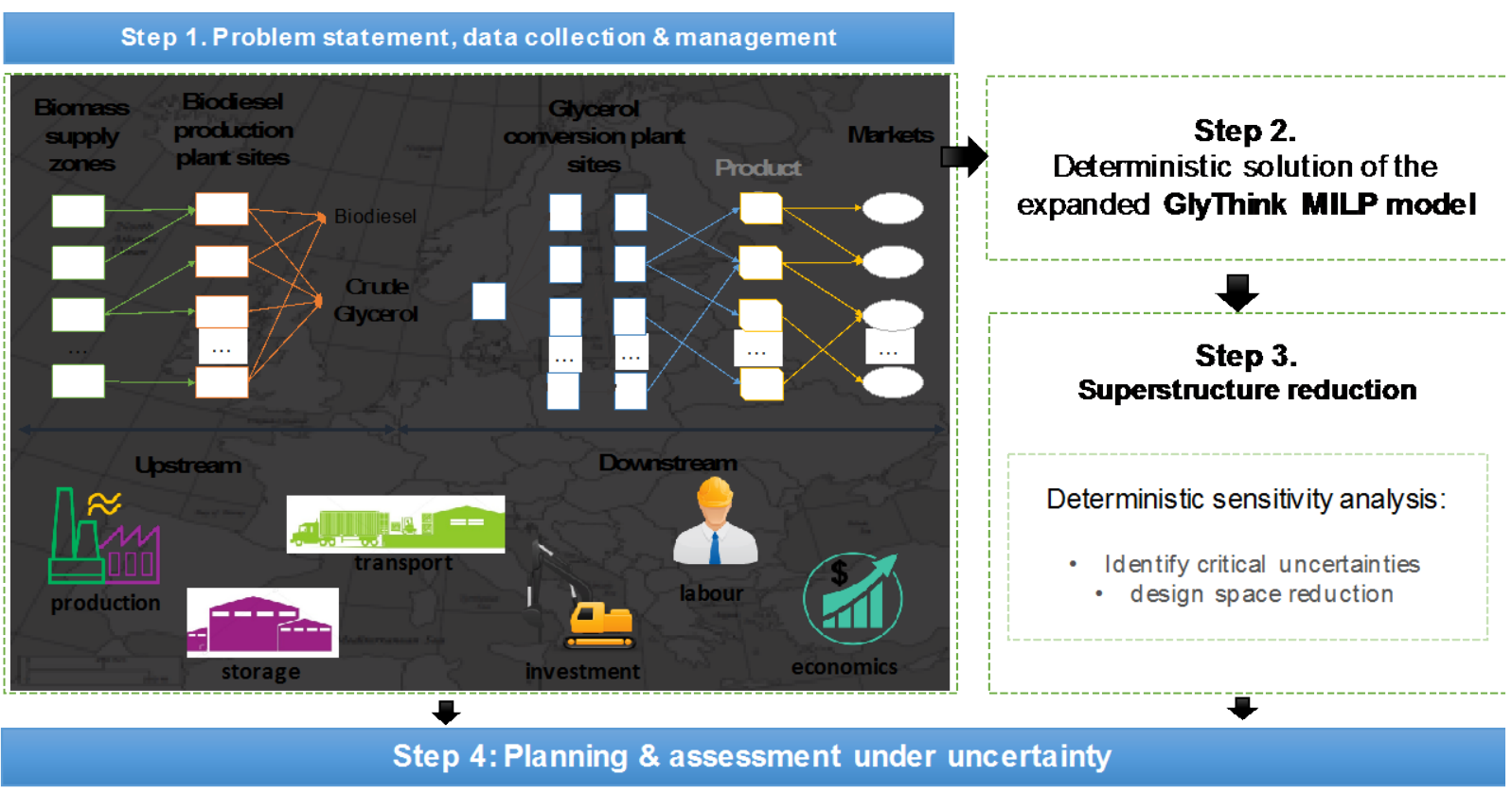

Step 4.1. Monte Carlo - sample generation
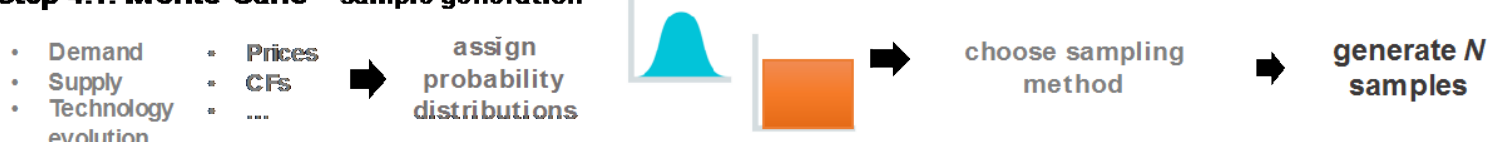

Two-stage stochastic MILP: 2S-GlyThink

\section{Step 4.2. Solution under uncertainty}

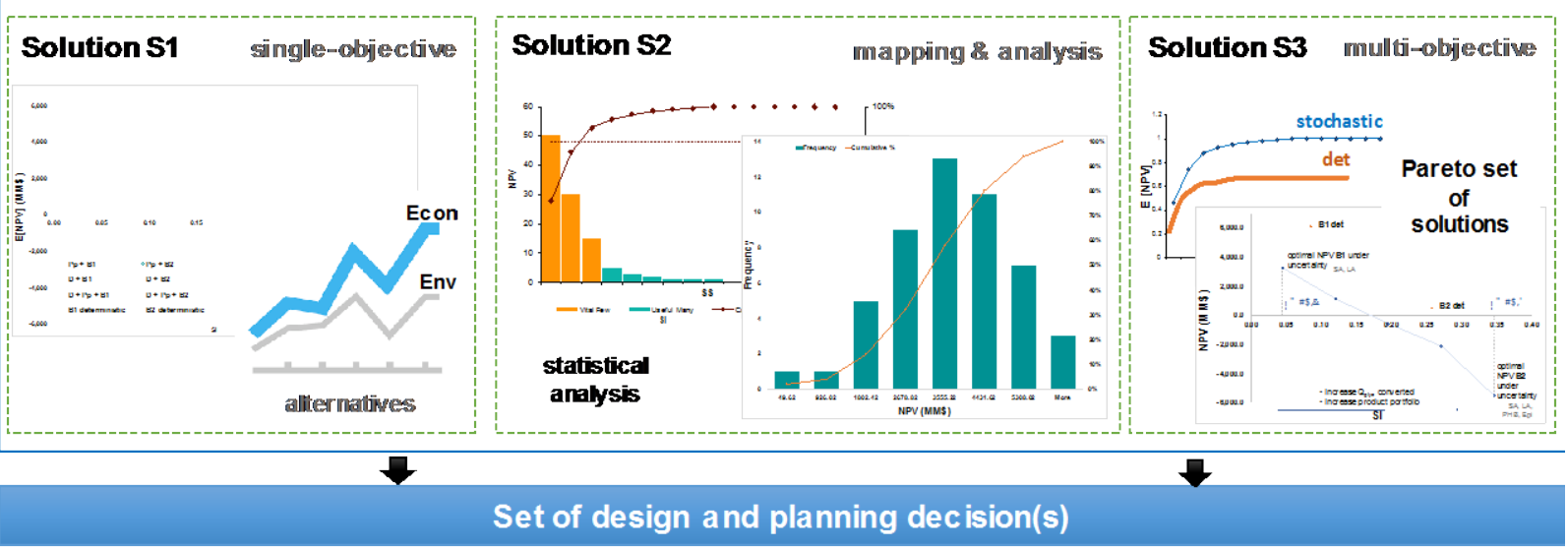

Figure 1: Framework for optimal early-stage design and planning of biorefinery supply chains under uncertainty. 


\section{Step 1: Problem statement, data collection and management}

In this step of the methodology, the problem is identified by stating the goals, objectives and the scope of the case study under analysis.

Glycerol is an immediate by-product of the biodiesel industry, being produced independently of the raw material used for the biodiesel manufacture. Since it is nowadays a surplus product, with low market prices, it may lead to a potential environmental problem as it cannot be directly disposed into the environment (63). Thus, in this work, the aim is to optimize the supply chain of the glycerol-based biorefinery, which is defined by a three-echelon SC (supplier-plant-market) as presented in Figure 2. It includes five stages and they are as follows: 1) transportation of crude glycerol from the biodiesel production plants to the glycerol conversion plant site(s); 2) glycerol purification process; 3) process of glycerol conversion into value added products; 4) product separation and purification process; and, 5) distribution of the products to the final markets.



Figure 2: Three-echelon glycerol-based biorefinery supply chain (suppliers-plants-markets).

As stated, the objective of this study is to maximize the Net Present Value, while accounting for the environmental impact associated with the glycerol-based integrated biorefinery supply chain under uncertainties, by determining the following design/strategic and planning/operational decision variables:

- location of glycerol suppliers and related logistics;

- the number, capacities, locations, and technologies for the biorefinery plants;

- glycerol inflow consumed for each selected biorefinery;

- product portfolio, production scale and storage levels at the plant locations for each time period; and, - product quantities to be delivered from plants to the demand sinks.

Furthermore, a key aspect is how to assess the alternatives in the design space also regarding environmental considerations. In this work, the single indicator is used as comparison metric, which is estimated based upon the LCA principles. As described in the literature review (section 2), its calculation follows the four main LCA 
steps (64). In this study, the boundaries of analysis for the LCA are limited to the sphere of the supply chain defined in Figure 2, which includes the 5 stages described. Correspondingly, the required data to estimate the environmental impact categories is collected, which consists of the mass and energy balances for all the operations included within the system boundaries (14).

In summary, the data concerning the characterization of technologies, logistics and characterization factors of LCA is collected and the superstructure reflecting all possible alternatives is generated. Therefore, this is the main input for the next step of the proposed methodology.

\section{Step 2: Deterministic formulation}

To address the optimal design and planning of the glycerol-based biorefinery supply chain, a multi-period, multi-stage and multi-product Mixed Integer Linear Programming optimization model, called GlyTbink has been proposed in (5). In this step, the GlyThink model is extended to include the environmental impact assessment calculations, and it can be formally stated as follows.

Overall, given:

- a possible superstructure of the integrated glycerol-based biorefinery supply chain combining crude glycerol acquisition, plant site locations, upgrading technologies and distribution logistics;

- a fixed time horizon divided into a set of time periods, corresponding to the typical biorefinery lifetime in terms of years;

- a set of crude glycerol suppliers and a maximum supply available per supplier;

- crude glycerol composition;

- a set of potential products to be produced from glycerol;

- a set of available production, separation and purification technologies and corresponding yields;

- a set of potential locations for the construction of the biorefinery(ies);

- a set of potential markets and corresponding demands;

- distances between nodes of the supply chain structure;

- crude glycerol, utilities and product prices;

- labor cost dependency on production capacity;

- transportation capacity and related costs;

- upper and lower bounds for each technology's capacity level;

- process and economic models (such as fixed capital investment calculation);

- financial data (such as interest and tax rates); 
- environmental emissions linked to the activities and operations of the network;

- characterization factors $(\mathrm{CFs})$ to convert the data inventory to damage impact categories (obtained from ReCipE.

Considering the maximization of the Net Present Value, the model solution leads to the identification of the optimal design/strategic and planning decisions as follows:

- Location of glycerol suppliers and related logistics;

- The number, capacities, locations (single- or multi-plant), and technologies for the biorefinery plants;

- Glycerol inflow consumed for each selected biorefinery;

- Product portfolio, production scale and storage levels at the plant locations for each time period; and,

- Product quantities to be delivered from plants to the demand sinks.

The complete description of the model and the corresponding mathematical formulation is presented in (5). As stated, in this work, the GlyThink model is extended to include the estimation of the environmental impact. The mathematical description of the life cycle assessment of the SC (formulated in this paper) is firstly obtained by estimating the life cycle inventory of the SC activities/operations, whose related emissions can be expressed as a function of continuous decision variables of the model. Thus, the energy consumption, chemicals, solvents and catalysts used are cataloged and quantified, alongside with wastes released to the environment. The mathematical description of the SC activities and operations as shown in Figure 2 is presented in Eq. (1).

$$
\begin{aligned}
& L C I_{i, t}=\sum_{z}^{Z} \sum_{x}^{X} \sum_{k}^{K} \lambda_{t, i, i} \cdot \frac{F_{g, k, x, z, t}^{i n}}{L} \cdot 2 \cdot D_{z, x} \cdot A v C o n s+ \\
& \sum_{z}^{Z} \sum_{x}^{X} \sum_{k}^{K}\left(\lambda_{e s_{i, k}}+\lambda_{s l_{i, k}}+\lambda_{e n_{i, k}}\right) \cdot F_{g, k, x, z, t}^{i n}+ \\
& \sum_{x}^{X} \sum_{k}^{K} \lambda_{e n_{i, k}} \cdot F_{b, k, x, t}+ \\
& \sum_{t}^{T} \sum_{x}^{X} \sum_{k}^{K}\left(\lambda_{e s_{i, k}}+\lambda_{s l_{i, k}}+\lambda_{e n_{i, k}}+\lambda_{p l_{i, k}}\right) \cdot F_{p, k, x, t}+ \\
& \sum_{x}^{X} \sum_{i}^{I_{p}} \sum_{m}^{M} \lambda_{t r, i} \cdot \frac{F t r_{i, x, m, t}}{L} \cdot 2 \cdot D_{x, m} \cdot f c \\
& \forall i \in I_{p} \wedge k \in K \wedge q \in Q \wedge x \in X \wedge z \in Z \wedge t \in T
\end{aligned}
$$

In this equation $\lambda_{t r, i}, \quad \lambda_{c s_{i, k}}, \lambda_{s l_{i, k}}, \lambda_{e n_{i, k}}$ and $\lambda_{p l_{i, k}}$, represent the life cycle inventory entries (released emissions) per stage related to the flow of the component used as reference. For example, $\lambda_{e n_{i, k}}$, represents the emissions of component $i$ linked to the usage of energy per unit of reference component flow in 
technology $k$ at plant $x$ in time $t$. The remaining details of the parameters are described in the nomenclature section. The next step is to convert the gathered data into a meaningful group of environmental impact categories. This is achieved by using damage models that connect the emissions to their consequent environmental damage.

$S_{c}=\sum_{i}^{I_{c}} L C I_{i} \times C F_{i, c}$

Consequently, in this study, these are then normalized and weighted in order to be aggregated into a single indicator (single indicator, SI).

$S I=\sum_{c}^{c} S_{c} \cdot w_{c}$

where, $w_{c}$ are the weighting factors. Since the LCIA method has been decided upon in the Step 1 of the methodology, the $C F_{i, c}$ and the $w_{c}$ are then correspondingly selected.

The output of this step is the deterministic solution of the extended GlyThink model which will be used for comparison with the model solution after the superstructure reduction performed in the next step of framework.

\section{Step 3: Superstructure reduction}

The aim of Step 3 of the methodology is to decrease the complexity of the optimization problem in order to decrease the computational effort, so that a stochastic model can be run. This is attained by reducing the superstructure that will be further handled and optimized through stochastic modeling (in Step 4).

To this end, the first stage is to select the sources of uncertainty that one knows, through literature research and/or expert knowledge on similar problems, that might affect significantly the feasibility and optimality of the network. In this study, the input sources that might carry uncertainty are categorized into endogenous or exogenous sources. The former might be derived from the data collection step, if data is obtained from different sources, for example regarding the estimation of the fixed capital investment. The exogenous sources of uncertainty are given by the intrinsic variability, such as prices forecast and market demands, among others. After identifying the potential sources of uncertainty, the impact of the propagation of input uncertainties to the model outputs of interest, such as the economic objective function and the environmental criteria, is quantified. This is achieved through a comprehensive scenario-based sensitivity analysis, which applies the extended deterministic model presented in Step 2. Analyzing the influence of the input variation of the uncertain parameters on: (i) the objective functions (economic -NPV and environmental- LCA); and, (ii) SC design, one can ascertain a set of SC structures (links) that are consistently not selected under extreme 
variation of the parametric uncertainties. In this way, the superstructure can be reduced by removing the links that are not utilized, leaving only the links corresponding to the SC structures mostly selected.

Henceforth, the outcome of this step is twofold: (i) the identification of parameters that have high impact on the model outputs (uncertainty domain); and, (ii) a reduced superstructure obtained by eliminating the links that are not used when subject to extreme variation of uncertainty factors.

\section{Step 4: Planning and assessment under uncertainty}

This part of the methodology intends to provide the user with a tool to deal with inherent uncertainty by explicitly incorporating it into the decision-making. To this end, in step $4.1 \mathrm{NS}$ samples are generated that represent NS possible future uncertain events; in step 4.2, the two-stage stochastic model is developed; and, in step 4.3, a thorough assessment is proposed in the form of three solution approaches for the decision under uncertainty (S1, S2 and S3).

\section{Step 4.1: Monte Carlo technique}

The sources of uncertainty identified in the step 3 as being the ones having more effect on the model outputs and SC structures, are now represented in terms of probability distribution functions (e.g. normal, log-normal, uniform, etc.), with characteristic parameters (e.g. mean and standard deviation for normal distribution). When possible, the density functions are built upon historical data. However, this information is often not available in the early stage of process design, especially regarding new biotechnological routes. Therefore, in these circumstances, expert knowledge is used, where typical ranges of variation are inferred and uncertainty classes are assigned. Furthermore, possible correlation between the input sources of uncertainty are analyzed, and if present they are defined by estimating the pairwise covariance. Henceforth, the uncertainty domain obtained in step 3 is used as input data for the Monte Carlo sampling, where Latin Hypercube sampling with Iman and Conover rank correlation control is used, leading to a set of samples (representing future equally probable uncertainty events). This set of samples is employed as discretization points to approximate the probability integral in the objective function of optimization problem under uncertainty, as presented in the next step of the framework.

\section{Step 4.2: Stochastic mathematical formulation - 2S-GlyThink model}

In this step of the framework, uncertainty is explicitly incorporated by reformulating the extended version of the GlyThink model (5) developed in Step 2, into a two-stage stochastic optimization problem, called $2 S$ GlyThink. 
Decisions concerning the design and planning of the biorefinery supply chain are made in two stages: the $1^{\text {st }}$ stage decisions ('here-and-now') are taken before the exact realization of uncertainty; and the $2^{\text {nd }}$ stage decisions are made after the realization of uncertainty ('wait-and-see'), being therefore adjustable to its occurrence, also called recourse or corrective actions. In this work, the $1^{\text {st }}$ stage decisions are the initial production capacities of the plants and their capacity expansions over the time horizon, thus directly associated with the fixed investment of the project which has to be taken in the beginning of the time horizon. The $2^{\text {nd }}$ stage decisions consist of planning decision variables, such as inflow of raw materials, production levels and flow of products to the market sinks, and they are graphically depicted in Figure 3.

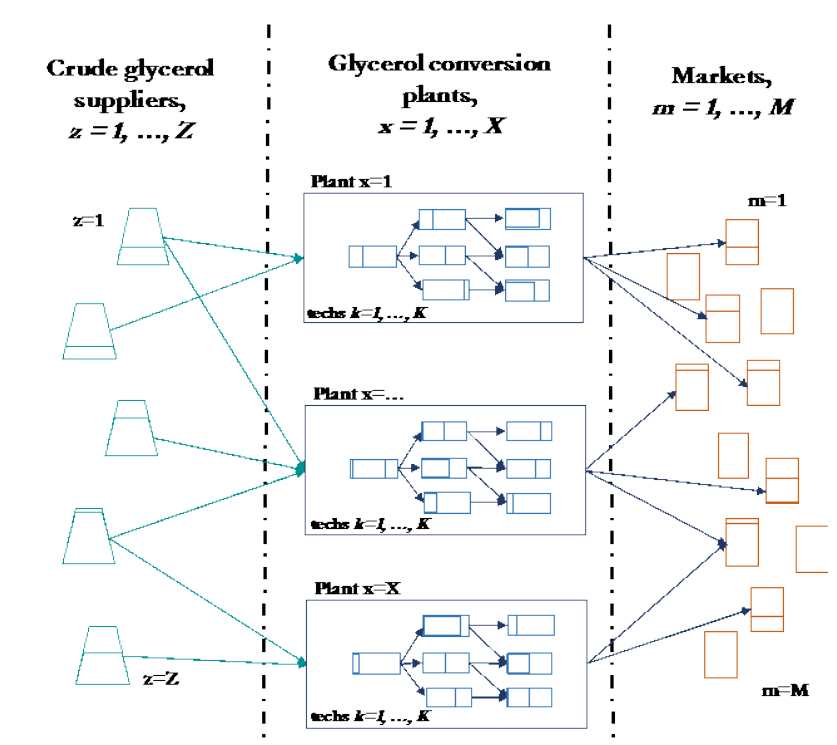

Figure 3: Exemplification of the planning decisions as $2^{\text {nd }}$ stage variables to be identified through solving the 2S-GlyThink model.

To achieve this, the $2 S$-GlyThink model is formulated as a multi-period, multi-product and multi-stage (threeechelon) MILP, targeting at maximizing the NPV of the corresponding SC structure. The following sections describe in length the variables and constraints of the 2 S-GlyThink model.

The mathematical formulation of the 2 S-GlyThink, is developed so as to allow the flow delivered between the suppliers and plant site locations, production levels, and flows transported to the markets, and associated costs to change with time and with uncertain event realization. The model constraints are grouped into $1^{\text {st }}$ stage constraints that include (4) to (13) and $2^{\text {nd }}$ stage constraints which includes constraints (14) to (23). The economic objective function is presented in Eq. (25). The definitions of the sets, variables and parameters are given in the end of this article.

\section{$1^{\text {st }}$ stage constraints}

A binary variable, $y_{k, q, x, t}$, is introduced in constraints (4) and (5), to impose the selection of technologies $k$, with capacity level $q$, in biorefinery location $x$, and time period $t$. 


$$
\begin{aligned}
& \sum_{x}^{X} y_{k, q, x, t} \geq 1, \forall k \in K \wedge q \in Q \wedge t \in T \\
& \sum_{x}^{X} y_{k, q, x, t} \leq N_{x}, \forall k \in K \wedge q \in Q \wedge t \in T
\end{aligned}
$$

where $y_{k, q, x, t}$ is equal to 1 if technology $k$ with capacity level $q$ is built at location $x$ and time period $t$, and corresponds to the total number of plant site locations available for the construction of the biorefineries. Constraint (4) and constraint (5) state that at least one and at most $N_{x}$ locations can be simultaneously selected for the construction of the biorefinery(ies). Also, as stated in constraint (6), if at time period $t$, technology $k$ with capacity level $q$ is selected to be built at plant site location $x$, then it is assumed that it must be selected/open during all time periods greater than $t$.

$y_{k, q, x, t+1} \geq y_{k, q, x, t}, \forall k \in K \wedge x \in X \wedge q \in Q \wedge t \in T-1$

The convex hull technique has been used to linearize the power law equation for the estimation of the fixed capital investment, as proposed in (5). The obtained algebraic equations are as follows.

$$
\begin{aligned}
& \sum_{q}^{Q} y_{k, q, x, t} \leq 1, \forall k \in K \wedge x \in X \wedge t \in T \\
& \sum_{q}^{Q} h_{k, q, x, t}^{\prime}=\frac{1}{N S} \cdot \sum_{s}^{N} \sum_{i}^{I_{p}} F_{i, k, x, t, s}, \forall s \in N S \wedge i \in I_{p} \wedge k \in K \wedge x \in X \wedge t \in T \\
& H_{k, q}^{m i n} \cdot y_{k, q, x, t} \leq h_{k, q, x, t}^{\prime} \leq H_{k, q}^{m a x} \cdot y_{k, q, x, t}, \forall k \in K \wedge q \in Q \wedge x \in X \wedge t \in T \\
& C_{k, q, x, t}=b_{k, q, x} \cdot y_{k, q, x, t}+s l o p e_{k, q, x} \cdot h_{k, q, x, t}^{\prime}, \forall k \in K \wedge q \in Q \wedge x \in X \wedge t \in T \\
& C_{k, q, x, t} \leq c_{k}^{m x} \cdot y_{k, q, x, t}, \forall k \in K \wedge q \in Q \wedge x \in X \wedge t \in T \\
& F C I_{k, x, t}=6.7 \cdot \sum_{q}^{Q} C_{k, q, x, t}, \forall q \in Q \wedge k \in K \wedge x \in X \wedge t \in T \\
& C_{0}=\sum_{x}^{X} \sum_{k}^{K} F C I_{k, x, t=1}+\sum_{t}^{T}\left[\sum_{x}^{X} \sum_{k}^{K} F C I_{k, x, t}-\sum_{x}^{X} \sum_{k}^{K} F C I_{k, x, t-1}\right] \\
& \forall k \in K \wedge x \in X \wedge t \in T
\end{aligned}
$$

Firstly, only one segment $q$ per technology $k$ at location $x$ in time period $t$ can be selected, as presented in Eq. (7). In Eq. (8), the continuous variable representing the flow rate in $k$ is disaggregated for each segment $q$, $b^{\prime} k, q, x, t$. This is set to be the expected average of the total flow of components leaving technology $k$, at location $x$ and in time period $t$, over the range of uncertainties $s \in N S$. The disaggregated variable representing the cost, $C_{k, q, x, t}$ is estimated as presented in Eq. (10). Lastly, upper and lower limits are set for the disaggregated variables as presented in (9) and (11) for the flow and cost, respectively. 
For all other remaining instances, the Boolean and binary variables are false and 0 , respectively. Therefore, as the upper boundaries are given by constraints (9) and (11) for the segments not selected, the associated continuous disaggregated variables are 0 ; and, the variables that can have values higher than 0 are the ones obtained for the disjunctive term selected. Furthermore, Eqs. (8) and (12) state that the continuous variables are equal to the disaggregated variables for the disjunctive term chosen, and their relationships are described through these disaggregated variables by constraints (8), which is only active when the related binary variables are 1.

\section{$2^{\text {nd }}$ stage constraints}

The mass balance must hold for each node within the network. Therefore, the overall mass balance for each component $i$ in technology $k$ at plant site location $x$ at each time period $t$ and scenario $s$ is set by Eq. (14). For each technology $k$ at site location $x$ in time period $t$ and scenario $s$, the inflow of $i\left(F_{i, k, x, t, s}^{i n}\right)$ plus the amount of $i$ produced $\left(P r_{i, k, x, t, s}\right)$, must be equal to the amount of $i$ separated as waste $\left(W_{i, k, x, t, s}\right)$ plus the output flow $\left(F_{i, k, x, t, s}\right)$ to be delivered to the customers or to be stored in location $x$.

$$
\begin{aligned}
& \sum_{z}^{Z} \operatorname{Raw} M_{i, z, x, t, s}+\sum_{k}^{K_{c a n v}} P r_{i, k, x, t s}+\alpha_{i, k} \cdot \sum_{k}^{K} U_{i, k, x, t, s}=\sum_{k}^{K_{G P} \cup K_{S P}} W_{i, k, x, t, s}+\sum_{k}^{K_{S P}} F_{i, k, x, t, s} \\
& \forall i \wedge I \wedge x \in \mathrm{X} \wedge t \in T \wedge s \in N S
\end{aligned}
$$

Furthermore, in Eq. 14, $K_{\text {conv }}$ represents the set of technologies used for the conversion of raw materials into value-added products, and finally $K_{S P}$, represents the set of technologies to be used for the separation and purification of the above-mentioned products. Also, $\alpha_{i, k}$ is the fraction of a chemical or utility mixed with the process stream $\left(I_{u t}\right)$, being 1 if the utility/chemical/solvent $\mathrm{i}$ is directly added to the flow stream (e.g. direct steam), and 0 otherwise (e.g. cooling water). The amount of component $i$ produced or consumed in the conversion technologies, $\left(\operatorname{Pr}_{i, k, x, t, s}\right)$, is given in Eq. (15).

$$
\sum_{k}^{K_{c a n v}} \operatorname{Pr}_{i, k, x, t, s}=\sum_{k}^{K_{c a r r}} \sum_{r}^{R} \sum_{r c t}^{R r t} \gamma_{i, k, r} \cdot \theta_{r t, k, r} \cdot F_{r t t, k, x, t, s}^{i n}, \forall i \in I \wedge x \in X \wedge t \in T \wedge s \in N S
$$

where, $\gamma_{i, k, r}$ and $\theta_{i, k, r}$ represent reaction stoichiometry for each component $i$ in technology $k$ and reaction $r$, and conversion of key reactant $i$ in technology $k$ where $r$ occurs, respectively. The total amount of chemicals or utilities consumed/added $i$ is obtained as a fraction of the total flow in the technologies $k$ and it is given in Eq. (16) as follows.

$$
\sum_{k}^{K_{c a n v}} \operatorname{Pr}_{i, k, x, t, s}=\mu_{i, k} \cdot \sum_{i}^{I \notin I_{t d}} F_{i, k, x, t, s}^{i n}, \forall i \in I_{u t} \wedge x \in X \wedge t \in T \wedge s \in N S
$$

where, $\mu_{i, k, r}$ is the fraction of chemicals/solvent $i \in I_{u t}$ s mixed with the process stream in technology $k$. 
In constraint Eq. (17) the inflow of component $i \in I_{r m}$ into plant site location $x$ coming from supplier $z$ in time period $t$ and in scenario $s,\left(\operatorname{Raw} M_{i, z, x, t, s}\right)$, is enforced to be lower than or equal to the total amount of $i$ available from supplier $z$ in time period $t\left(\phi_{i, z, t}\right)$.

$$
\begin{aligned}
& \sum_{x}^{X} \operatorname{Raw} M_{i, z, x, t, s} \leq \phi_{i, z, t}, \forall i \in I_{\text {feed }} \wedge z \in Z \wedge t \in T \wedge s \in N S \\
& \sum_{x}^{X} \sum_{z}^{Z} \operatorname{Raw}_{i, z, x \neq, s} \leq \sum_{z}^{Z} \phi_{i, z f}, \forall i \in I_{\text {feed }} \wedge t \in T \wedge s \in N S \\
& \sum_{i}^{I_{\text {fend }}} \operatorname{Raw} M_{i, z, x, t, s} \leq L \cdot T_{z, x, t, s}, \forall x \in X \wedge z \in Z \wedge t \in T \wedge s \in N S
\end{aligned}
$$

Furthermore, constraint (18) imposes that the maximum flow of raw material $i$ delivered to all locations $x$ coming from all suppliers $z$ cannot exceed the total amount of raw materials $i$ available from all suppliers $z$ in time period $t$. Finally, constraint (19) sets the total flow of raw materials to be delivered to the plant site locations $x$ to be lower or, at most, equal to the available transportation capacity over the planning timeperiod.

Constraint (20) sets the maximum limit of product being transported to the markets $m, F t r_{p, x, m, t, s}$, as the maximum amount of product $p$ being produced at plant site $x$ in time period $t$ and scenario $s$, where the $S t_{i, k, x, t, s}$ is the amount of product $i$ to be stored at location $x$, in time period $t$ and scenario $s$. Constraint (21) enforces that, the amount of product $p$ delivered to a market $m$ must not exceed the demand in that same market $m$. Furthermore, constraint (22) imposes that the maximum flow of product $p$ delivered to all markets $m$ cannot exceed the total demand of product $p$ in all markets $m$. Finally, constraint (23) sets the product flow delivered to the markets $\left(F t r_{p, x, m, t, s}\right)$ to be lower or, at most, equal to the available transportation capacity over the planning time-period.

$$
\begin{aligned}
& F r_{i, x, m, t, s}+\sum_{k}^{K} S t_{i, k, k, t, s} \leq \sum_{k}^{K} F_{i, k, x, t, s}, \forall i \in I_{p} \wedge x \in X \wedge m \in M \wedge k \in K_{S p} \wedge t \in T \wedge s \in N S \\
& \sum_{x}^{X} F t r_{i, x, m, t, s} \leq D_{p, m, t, s}, \forall i \in I_{p} \wedge m \in M \wedge t \in T \wedge s \in N S \\
& \sum_{x}^{X} \sum_{m}^{M} F t r_{i, x, m t, s} \leq \sum_{m}^{M} D_{p, m, t, s}, \forall i \in I_{p} \wedge m \in M \wedge t \in T \wedge s \in N S \\
& F t r_{p, x, m, t, s} \leq L \cdot T_{p, x, m, t, s}, \forall m \in M \wedge \in T \wedge s \in N S
\end{aligned}
$$

Furthermore, the environmental impact assessment calculations presented in Eqs. 1 to 3 are reformulated in order to include uncertainty in the material flows, but it is unnecessary to repeat the equations here. 


\section{Objective function}

As previously mentioned, in this work, the measure of economic performance is given by the Net Present Value (NPV) as the objective function of the supply chain, and it is presented as follows. The NPV $\mathrm{s}_{\mathrm{s}}$ estimated as the sum of yearly cash-flows discounted to the present year, at a specific interest rate $(\omega)$, and as presented in Eq. (24) is determined as follows.

$$
\begin{aligned}
N P V_{s}=\sum_{t} \frac{C F_{t, s}}{(1+\omega)^{t}} & =\sum_{t} \frac{N E_{t, s}}{(1+\omega)^{t}}-C_{0}=A P V-C_{0} \\
= & \sum_{t}\left[\frac{1}{(1+\omega)^{t}}\right. \\
\cdot & {\left[S_{t, s}-P C_{t, s}-L c_{t, s}-\operatorname{Tr} C_{t, s}-S C_{t, s}-W C_{t, s}\right.} \\
- & {\left.\left.\left[\varphi \cdot\left(S_{t, s}-P C_{t, s}-L c_{t, s}-\operatorname{Tr} C_{t, s}-C D_{t, s}\right)\right]\right]\right]+C_{0} \cdot\left(\frac{s v}{(1+\omega)^{T}}-1\right), \forall s \in N S }
\end{aligned}
$$

Finally, the NPVs is fully given by Eq. (25).

$$
\begin{aligned}
& N P V_{s}=\sum_{t}\left[\frac{(1-\varphi)}{(1+\omega)^{t}}\right.
\end{aligned}
$$

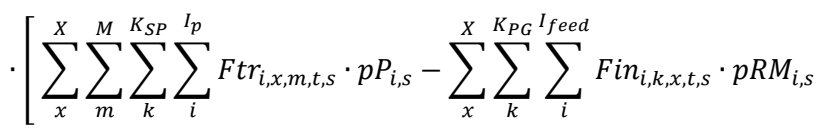

$$
\begin{aligned}
& -\sum_{x}^{X} \sum_{k}^{K_{c o n v} K_{S P}} \sum_{i}^{I_{u t}} U_{, s i, k, x, t} \cdot p U T_{i}-o p \cdot n s \cdot a v S a l_{t} \cdot \sum_{x}^{X} \sum_{k}^{K_{P G}} \sum_{i}^{I_{\text {feed }}} F i n_{i, k, x, t, s} \\
& -\sum_{x}^{X} \sum_{m}^{M} \sum_{i}^{I_{p}}\left[T_{i, m, x, t, s} \cdot\left(2 \cdot d_{x, m} \cdot(f c \cdot p F+\operatorname{trMa})+\left(\frac{2 \cdot d_{x, m}}{s p}+l u t\right) \cdot d w\right)\right] \\
& -\sum_{x}^{X} \sum_{z}^{Z}\left[T_{z, x, t, s} \cdot\left(2 \cdot d_{z, m} \cdot(f c \cdot p F+\operatorname{trMa})+\left(\frac{2 \cdot d_{z, m}}{s p}+l u t\right) \cdot d w\right)\right]-2 \cdot \operatorname{trGE} E_{t} \\
& \left.\left.-\sum_{x}^{X} \sum_{k}^{K_{S P}} \sum_{i}^{I_{p}} S t_{i, k, x_{,} s t} \cdot p S t_{i}-\left(w c_{t}+m s_{t}\right) \cdot C_{0}\right]+\frac{\varphi}{(1+\omega)^{t}} \cdot \lambda_{t} \cdot C_{0}\right]+\left(\frac{s v}{(1+\omega)^{T}}-1\right) \cdot C_{0}
\end{aligned}
$$

\section{Step 4.3: Solution under uncertainty}

In this step of the methodology, three solution approaches for an informed decision under uncertainty are given to decision-maker (S1, S2 and S3). These solutions are based upon: (S1) the stochastic single-objective 
optimization maximizing the NPV of the SC; (S2) detailed analysis, by mapping the SC structures of all solutions obtained from the implementation of the Monte-Carlo method; and, (S3) the stochastic multiobjective optimization, maximizing the NPV and minimizing the environmental impact of the supply chain.

\section{Solution S1 - stochastic single-objective optimization}

The main goal of the mathematical formulation is to maximize the expected value of the Net Present Value (NPV) as presented in Eq. (26). The MILP formulation can be expressed as follows:

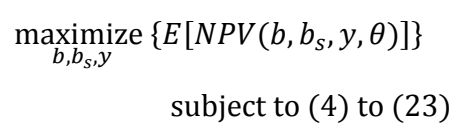

where, $b$ represents $1^{\text {st }}$ stage decision variables, $b_{s}$ represents $2^{\text {nd }}$ stage variables (planning) that are scenario dependent and $y$ stands for the binary variables. $\theta$ is the vector of uncertain data and the $E\left[N P V\left(b, b_{s}, y, \theta\right)\right]$ is the expected value of the objective function NPV over the $\theta$ space.

The estimation of the expected value of the objective function (in this case, NPV) requires the evaluation of a multi-dimensional probability integral. Thus, in large problems the evaluation of this integral might result in a heavy and complex procedure, thus requiring high computational effort. Therefore, a common way to tackle this in stochastic programming is based upon the Monte Carlo sampling method for the approximation of the expected value of the objective function called Sample Average Approximation (65). In this approach, as also mentioned above, the generated set of samples is employed as discretization points to approximate the probability integral. This is exemplified in Eq. (27), where the expected value of the objective function $E[N P V]$ is approximated by the expected value of the resulting distribution. In the latter equation, $p r_{s}$ is the probability of occurrence of a certain scenario $s$ and NS is the total number of scenarios $s$.

$E\left[N P V\left(b, b_{s}, y, \theta\right)\right] \approx \sum_{S}^{N S}\left(p r_{s} \cdot N P V\left(b, b_{s}, y, \theta_{s}\right)\right)=\frac{1}{N S} \sum_{S}^{N S} N P V\left(b, b_{s}, y, \theta_{s}\right)$

Therefore, the optimization problem is finally expressed as,

$\underset{b, b_{s}, y}{\operatorname{maximize}} E\left[N P V\left(b, b_{s}, y, \theta\right)\right]=\frac{1}{N S} \sum_{s}^{N S} N P V\left(b, b_{s}, y, \theta_{s}\right)$
subject to (4) to (23)

Given the (fixed) sample $s$ to $N S$, the function $E\left[N P V\left(b, b_{s}, y, \theta\right)\right]$ is deterministic, thus deterministic optimization algorithms can be used to solve the problem. 


\section{Solution S2 - SC structure mapping and analysis}

In this solution approach, the consequences of named uncertainties on the SC structure and, on the objective function, are mapped and analyzed. To this end, the deterministic optimization problem formulated in Step 2, is solved for each one of the samples generated in Step 4.1, as described by the problem formulation presented below in (29). This falls under the 'wait and see' category of optimization problems, since it is built on the premise that the decision-making will wait and be made upon the realization of the uncertain event. A distribution of the objective function values is achieved, i.e. a different objective function value is obtained for every sample, which corresponds to a certain design and planning SC structure. The application of this solution approach enables the analysis of the robustness of the SC structure, which highly contributes to an informed decision under uncertainty.

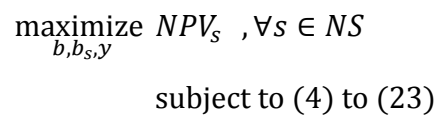

\section{Solution S3 - multi(bi)-objective}

The solution of S3 is given by a set of Pareto alternatives representing the optimal trade-offs between the two objectives, in order to manage the environmental consequences. In this study, these solutions are obtained via the $\varepsilon$-constraint method as defined in Ehrgott (2005) (66), which leads to the solution of the following singleobjective function for various instances of the parameter $\varepsilon$ :

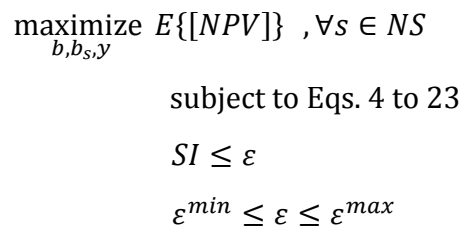

where $\varepsilon^{\min }$ and $\varepsilon^{\max }$ represent the upper and lower limits within which the parameter $\varepsilon$ must fall, which are given by the optimization of each separate objective function (economic-NPV and environmental-LCA). Therefore, $\varepsilon^{\mathrm{min}}$ is obtained following the mathematical formulation presented below.

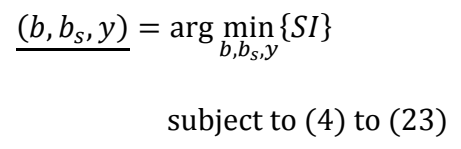

where, $\left(b, b_{s}, y\right)$ stands for, $1^{\text {st }}$ stage decision variables, $2^{\text {nd }}$ stage decision variables and binary variables that correspond to the optimal SC structure when minimizing the expected value of the SI as objective function. 


\section{Results \& Discussion}

\section{Step 1: Problem definition, data collection \& management}

This work, aims to identify the optimal supply chain of the glycerol-based integrated biorefinery in Europe under multi-level uncertainties. To this end, the starting point is to characterize the superstructure of alternatives obtained in a previous work for the glycerol conversion to chemicals and biofuels (5). However, in this study, this superstructure is focused to only include bio-based chemicals, based upon a price screening and based upon the fact that, through deterministic assessment, biofuels have not been selected as an economically sustainable alternative for the glycerol valorization $(5,6)$. Therefore, the superstructure of alternatives used is presented in Figure 4. Included in this network are: several alternative suppliers, plant site locations, technologies (and corresponding products), and demand sinks. The products included in the superstructure are: polyhydroxybutyrate (PHB), lactic acid (LA), succinic acid (SA), 1-2-propanediol (1,2PDO), 1,3-propanediol, (1,3-PDO), acrolein (Acro) and epichlorohydrin (Epi). The corresponding processing technologies are described in Table 2. The total glycerol availability in Europe is $4.10 \times 10^{6}$ ton/year (5). The suppliers are given by the current top- 5 major producers (and consumers) of biodiesel in Europe, and they are: Germany, France, Netherlands, Spain and Italy (5). The glycerol available per supplier is given in the supplementary material, in table SM1. The market demands for the above-mentioned products were collected from reports, publications and public communications. To be as much representative of the European market as possible, a total of 5 top markets were identified for each product and the corresponding demands were collected, they are reported in (5). The product prices needed for the economic analysis are presented in Table 3. Furthermore, regarding the data required for the environmental assessment, the ReCiPe method (46) was the life cycle impact assessment method (LCIA) selected (34), and thus all impact categories and characterization factors needed to convert the material flows into impact categories are defined, along with the normalization and weighting factors. 


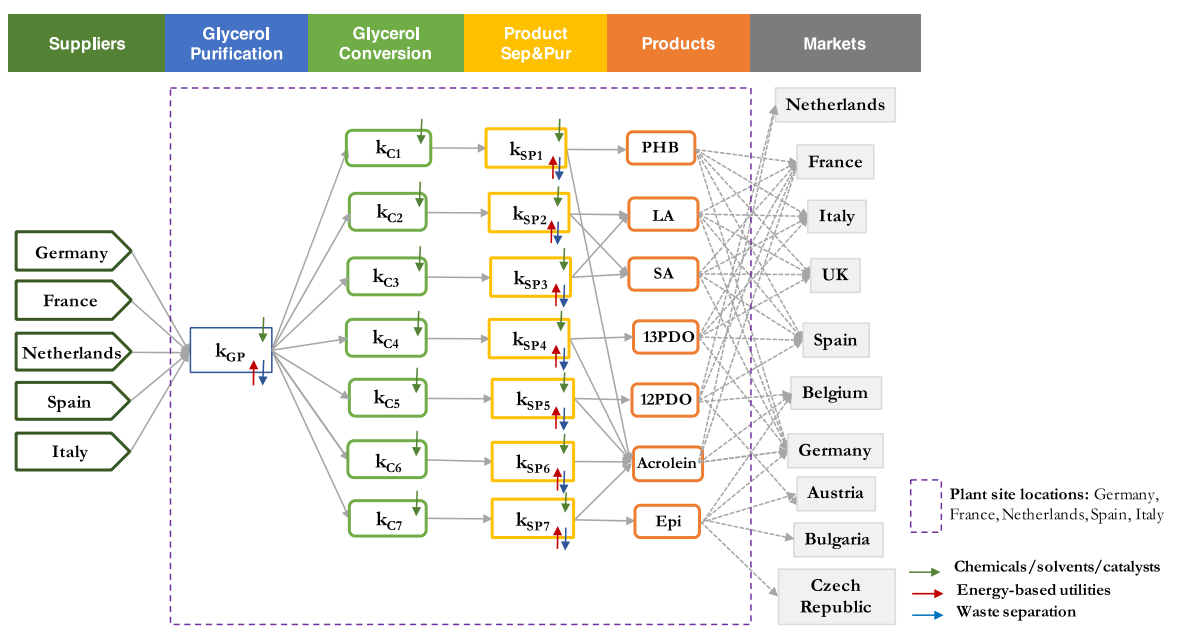

Figure 4: Superstructure representing the alternatives in the design space.

Table 2: Process description for all the alternatives in the superstructure (5).

\begin{tabular}{|c|c|c|}
\hline & Product & Technology Description \\
\hline $\mathrm{k}_{\mathrm{C} 1} \& \mathrm{k}_{\mathrm{SP} 1}$ & Polyhydroxybutyrate (PHB) & $\begin{array}{l}\text { Glycerol fermentation by an engineered strain of } C \text {. necator }+ \text { blending } \\
\text { w/ surfactant solution }+ \text { hypochlorite digestion centrifugation }+ \text { spray } \\
\text { drying }(67)\end{array}$ \\
\hline $\mathrm{k}_{\mathrm{C} 2} \& \mathrm{k}_{\mathrm{SP} 2}$ & Lactic acid (LA) & $\begin{array}{l}\text { Glycerol fermentation by an engineered strain of E. coli }++ \text { reactive } \\
\text { extraction w/ TOA and DCE }(68)\end{array}$ \\
\hline $\mathrm{k}_{\mathrm{C} 3} \& \mathrm{k}_{\mathrm{SP} 3}$ & Succinic acid (SA) & $\begin{array}{l}\text { Glycerol fermentation by an engineered strain of B. succinicis producens } \\
D D 1+\text { reactive extraction w/ TOA and } 1 \text {-octanol }(69,70)\end{array}$ \\
\hline $\mathrm{k}_{\mathrm{C} 4} \& \mathrm{k}_{\mathrm{SP} 4}$ & 1,3-propanediol (1,3-PDO) & $\begin{array}{l}\text { Glycerol fermentation by an engineered strain of } K \text {. pneumoniae }+ \text { reactive } \\
\text { extraction w/ isobutyraldehyde hydrophilic alcohol/salt mixture } \\
\left.\text { (ethanol } / \mathrm{K}_{2} \mathrm{HPO}_{4}\right) \cdot(71-73)\end{array}$ \\
\hline $\mathrm{k}_{\mathrm{C} 5} \& \mathrm{k}_{\mathrm{SP} 5}$ & 1,2-propanediol (1,2-PDO) & $\begin{array}{l}\text { Sequential processes of dehydrogenation-hydrogenation via } \\
\text { hydroxyacetone }(74,75)\end{array}$ \\
\hline $\mathrm{k}_{\mathrm{C} 6} \& \mathrm{k}_{\mathrm{SP} 6}$ & Acrolein & Glycerol dehydration (76) \\
\hline $\mathrm{k}_{\mathrm{C} 7} \& \mathrm{k}_{\mathrm{SP} 7}$ & Epichlorohydrin (Epi) & Glycerol hydrochlorination (77) \\
\hline
\end{tabular}

Table 3: Products market spot prices. The corresponding references are mentioned in between square brackets.

\begin{tabular}{|c|c|c|}
\hline Product & $\begin{array}{c}\text { Products } \\
\text { selling price } \mathbf{\$} \mathbf{k g}\end{array}$ & Std. \\
\hline PHB & $4.5(63)$ & $0.197(63)$ \\
\hline LA & $2.0(63)$ & $0.041(63)$ \\
\hline SA & $2.0(63)$ & $0.23(63)$ \\
\hline 1,3-PDO & $2.02(63)$ & $0.35(63)$ \\
\hline 1,2-PDO & $1.662(63)$ & $0.28(63)$ \\
\hline Acrolein & $2.0(63)$ & $0.27(63)$ \\
\hline Epichlorohydrin & $1.992(77)$ & $0.34(78)$ \\
\hline
\end{tabular}




\section{Step 2: Deterministic formulation}

The deterministic optimization problem defined is Step 2 is here solved. As proposed in (5), two scenarios were built to understand the influence of constraining the model to a certain production capacity. They are described as follows:

- Scenario B1: leads to the optimization of the supply chain network allowing the model to identify a combination of best plant site locations (allowing the selection of more than one plant), by also determining the optimal amount of glycerol converted into value added products, so that NPV is maximized;

- Scenario B2: the optimization problem set in B1 is further constrained to convert the total amount of glycerol available $\left(4.10 \times 10^{6}\right.$ ton/year), also allowing the selection of more than one plant, so that NPV is maximized.

The main characteristics of the optimal SC structures obtained for B1 and B2 are described in Table 4, also presented in (5) and in the supplementary material in Figures SM1 and SM2.

Table 4: Details on the deterministic solutions: B1 and B2.

\begin{tabular}{|c|c|c|c|}
\hline Scenarios & NPV MM $\$ \times 10^{3}$ & SI & SC structure main characteristics \\
\hline B1 & 6.12 & 0.085 & $\begin{array}{l}\text { Plant site locations: Germany, France, The Netherlands, Italy } \\
\text { Suppliers: Germany, France, The Netherlands, Italy } \\
\text { Products: SA, LA } \\
\text { Markets served: } \\
\text { LA - Germany, France, Italy } \\
\text { SA - UK, Spain, Germany, Italy, France } \\
\text { Q }_{\text {glyc }}=2.13 \times 10^{3} \text { kton/vear }\end{array}$ \\
\hline B2 & 0.452 & 0.257 & $\begin{array}{l}\text { Plant site locations: Germany, France, The Netherlands, Italy, Spain } \\
\text { Suppliers: Germany, France, The Netherlands, Italy, Spain } \\
\text { Products: SA, LA, PHB, Epi } \\
\text { Markets served: } \\
\text { LA - Germany, Italy, Spain } \\
\text { SA - UK, Spain, Germany, Italy, France } \\
\text { PHB - Germany } \\
\text { Epi - Germany, The Netherlands, Beloium, Spain }\end{array}$ \\
\hline
\end{tabular}

\section{Step 3: Superstructure reduction}

This step has a twofold objective: (i) to identify the parameters that have the highest impact on the objective function; and, (ii) to provide the user with a reduced superstructure by analyzing the SC structures obtained when subjecting the supply chain model to extreme variations of the input parameters, so as to reduce the problem complexity.

To this end, a scenario-based sensitivity analysis is performed based on the deterministic single-objective optimization of the NPV. The sources of uncertainty identified are based on the most common uncertainty 
sources studied in the works presented in the literature reviewed in Table 1. Therefore, in this work, the sources of uncertainty that are analyzed are: product demand, glycerol price, fuel price, product price, and technology evolution (FCI and glycerol conversion). According to the sources of uncertainty identified, a relevant set of scenarios was built as presented in Figure 5.



Figure 5: Scenarios analyzed through the deterministic sensitivity analysis.

The set of scenarios represented in Figure 5 were developed so as to analyze the impact of extreme variation of the parameter values on the (a) objective function- NPV; (b) consequences of external techno-economic uncertainties on the environmental impact - SI; and, (c) SC structure and product portfolio selected. The description of the scenarios is as follows:

- Pp-Sc1: variation to 0.50 and 1.50 of the original price value regarding all products, to represent extreme cases of price variation.

- Pp-Sc2: variation to 0.50 and 1.50 of the original price value regarding the most frequently selected products: SA, LA, PHB and Epi. To represent extreme cases of price variation for the products selected in the deterministic solution of B2.

- Pp-Sc3: variation to 0.50 and 1.50 of the original price value regarding the most frequently selected products: SA and LA. To represent extreme cases of price variation for the products selected in the deterministic solution of B1.

- D-Sc1: variation to 0.50 and 1.50 of the original demand value regarding all products, to represent extreme cases of demand variation.

- D-Sc2: variation to 0.50 and 1.50 of the original demand value regarding the most frequently selected products: SA, LA, PHB and Epi. To represent extreme cases of demand variation for the products selected in the deterministic solution of B2.

- D-Sc3: variation to 0.50 and 1.50 of the original demand value regarding the most frequently selected products: SA and LA. To represent extreme cases of demand variation for the products selected in the deterministic solution of B1. 
- D-Sc4: variation of demand following a normal distribution $(79,80)$ (with $10 \%$ standard deviation and the original value as expected value) for the twenty years of plant life time. This represents a more realistic scenario of demand variation along the plant life time.

- FCI-Sc1: variation to 0.50 and 1.50 of the original FCI value regarding all products, to represent extreme cases of FCI variation.

- FCI-Sc2: variation to 0.50 and 1.50 of the original FCI value regarding the most frequently selected products: SA, LA, PHB and Epi. To represent extreme cases of FCI variation for the products selected in the deterministic solution of B2.

- FCI-Sc3: variation to 0.50 and 1.50 of the original FCI value regarding the most frequently selected products: SA and LA. To represent extreme cases of FCI variation for the products selected in the deterministic solution of B1.

- Conv-Sc1: variation to 0.50 and 1.50 of the original conversion value of all products, to represent extreme cases of conversion variation.

- Conv-Sc2: variation to 0.50 and 1.50 of the original conversion value of the most frequently selected products: SA, LA, PHB and Epi. To represent extreme cases of conversion variation of the products selected in the deterministic solution of B2.

- Conv-Sc3: variation to 0.50 and 1.50 of the original conversion value of the most frequently selected products: SA and LA. To represent extreme cases of conversion variation of the products selected in the deterministic solution of B1.

- Pglyc-Sc1: variation to 0.50 and 1.50 of the original crude glycerol price, in order to represent extreme cases of crude glycerol price variation.

- pFuel-Sc1: variation to 0.50 and 1.50 of the original fuel price, used for the transportation by truck, in order to represent extreme cases of fuel price variation.

The deterministic sensitivity analysis results obtained by the single-objective optimization maximizing the NPV of the supply chain are graphically presented in Figure 6 for B1 conditions, and in supplementary material Figures SM3 and SM4 for B2 conditions. Furthermore, all corresponding SC structures were analyzed, and a summary of the main characteristics of the scenarios that show the highest variation of NPV is presented in Table 5 . 
Figure 6: Sensitivity analysis of the NPV (left), SI (right) and corresponding SC structure to parameter variation, corresponding to $\mathrm{B} 1$ conditions. Where Pp, FCI and Conv refers to the variation of product price, fixed capital investment and glycerol conversion, respectively.

Hence, significant insights on the consequences of these techno-economic uncertainties on the NPV, SI and corresponding SC structures are discussed below.

\section{Influence on the NPV}

The analysis of Figures 6 (left hand side) and SM3, shows that the sources of uncertainty that have the highest impact on the NPV are: product price, product demand and FCI. In more detail, by analyzing the NPV of the scenarios Pp-Sc1, Pp-Sc2 and Pp-Sc3 under B1 and B2 conditions, it can be observed that the Pp-Sc1 and Pp-Sc2 have approximately the same impact, i.e., the variation of all prices and the variation of prices of the products SA, LA, Epi and PHB lead to the same results, which supports the fact that in fact these are the most relevant products to be included in the design space. Similar conclusions are taken by looking at the scenarios where the demand and the FCI are under parametric variation.

\section{Influence on the SI}

As can be observed in Figures 6 (right hand side) and SM4 for scenarios corresponding to B1 and B2, respectively, through the analysis of the SI, both product price and demand uncertainties have a significant impact on the SC structures, and on the corresponding SI, under B1 and B2 conditions. Whereas in case of B1 conditions, the variation of the FCI only affects the NPV (Figures 6), where there is no variation on the SI of the corresponding solutions, i.e., the SC structure obtained through deterministic solution is robust regarding the effects of the variation of the FCI. However, under B2 conditions, when varying the FCI corresponding to the most frequently selected products (observed in FCI-Sc1 and FCI-Sc2, on Figure SM4 in the supplementary material), the SI is slightly changed. This is due to the fact that, to compensate the higher fixed investment costs of these products, and to fulfill the full conversion of the available glycerol, the 
production of SA and LA is decreased and the production of PHB increased, which leads to higher environmental impact. This is explained by the fact that production of PHB is a heavier consumer of utilities than the production of SA, LA and Epi.

Overall, higher variation on the NPV and SI is observed in scenario B2 conditions (Figures SM3 and SM4 in the supplementary material), since in this case the production is constrained to convert the total amount of glycerol available in Europe at a given year; while, in scenario B1 (Figure 6, left and right hand side) the production can be adjusted to the uncertain events in order to reach an optimal solution.

Table 5: Main characteristics of the SC structures corresponding do the highest variation of NPV. Where Pp and D stand for the product price and demand, respectively.

\begin{tabular}{|c|c|c|c|c|}
\hline Scenarios & $\Delta \boldsymbol{\theta}$ & NPV MM\$ $\times 10^{3}$ & SI & SC structure main characteristics \\
\hline \multirow[b]{2}{*}{$\mathrm{Pp}-\mathrm{Sc} 1+\mathrm{B} 1$} & $-50 \%$ & -7.329 & 0.084596 & $\begin{array}{l}\text { Plant site locations: Germany, France, Netherlands, Spain } \\
\text { Suppliers: Germany, France, Netherlands, Spain } \\
\text { Products: LA, SA } \\
\text { Markets served: } \\
\text { LA - Germany, France, Spain } \\
\text { SA - Germany, France, Spain, UK, Italy }\end{array}$ \\
\hline & $+50 \%$ & 22.129 & 0.30779 & $\begin{array}{l}\text { Plant site locations: Germany, France, Netherlands, Spain, } \\
\text { Italy } \\
\text { Suppliers: Germany, France, Netherlands, Spain, Italy } \\
\text { Products: LA, SA, Epi, PHB } \\
\text { Markets served: } \\
\text { LA - Germany, France, Spain, Italy } \\
\text { SA - Germany, France, Spain, UK, Italy } \\
\text { PHB - Germany } \\
\text { Epi - The Netherlands, Belgium }\end{array}$ \\
\hline \multirow{2}{*}{ Pp-Sc1+B2 } & \multirow[t]{2}{*}{$-50 \%$} & -21.010 & 0.25621 & $\begin{array}{l}\text { Plant site locations: Germany, France, Netherlands, Spain, } \\
\text { Italy } \\
\text { Suppliers: Germany, France, Netherlands, Spain, Italy } \\
\text { Products: LA, SA, Epi, PHB } \\
\text { Markets served: } \\
\text { LA - Germany, Italy, Spain } \\
\text { SA - Germany, France, Spain, UK, Italy } \\
\text { PHB - Germany } \\
\text { Epi - Germany, The Netherlands, Belgium, Spain }\end{array}$ \\
\hline & & 22.129 & 0.30779 & $\begin{array}{l}\text { Plant site locations: Germany, France, Netherlands, Spain, } \\
\text { Italy } \\
\text { Suppliers: Germany, France, Netherlands, Spain, Italy } \\
\text { Products: LA, SA, Epi, PHB } \\
\text { Markets served: } \\
\text { LA - Germany, Italy, Spain, France } \\
\text { SA - Germany, France, Spain, UK, Italy } \\
\text { PHB - Germany } \\
\text { Epi -The Netherlands, Belgium }\end{array}$ \\
\hline $\begin{array}{l}\text { D-Sc3 }+ \\
\text { B1 }\end{array}$ & $-50 \%$ & 3.050 & 0.04235 & $\begin{array}{l}\text { Plant site locations: France, Netherlands } \\
\text { Suppliers: France, Netherlands } \\
\text { Products: LA, SA } \\
\text { Markets served: } \\
\text { LA - Germany, France } \\
\text { SA - Germany, The Netherlands, UK, Spain, Italy }\end{array}$ \\
\hline
\end{tabular}


Based upon the previous analysis, the superstructure has been reduced based on the following observations: (i) the set of products selected is constant (see Table 5) and it is composed of SA, LA, PHB and Epi, thus the links corresponding to other products (technologies and markets) have been excluded; also, (ii) by analyzing the SC structures in Table 5, one can see a pattern of the most frequently selected links between production plants and markets. These are the ones kept in the reduced superstructure. Thus, taking these facts into consideration, the initial superstructure as presented in Figure 4 has been reduced to the one presented in Figure 7. Furthermore, since the products and the corresponding links identified as optimal in the deterministic solution for scenarios B1 and B2 have been kept as part of the reduced superstructure (see Table 4), the deterministic solutions corresponding to B1 and B2 scenarios after superstructure reduction are equal to the $\mathrm{SC}$ structures obtained for $\mathrm{B} 1$ and $\mathrm{B} 2$ before the superstructure reduction (whose characteristics have been reported in Table 4). In this way, the reliability of the reduced superstructure obtained is validated, which will then be the starting point of step 4 . 


\section{Step 4.2: Solution under uncertainty}

\section{Solution S1 - stochastic single-objective optimization}

In solution S1, the problem corresponding to the formulation of the stochastic single-objective optimization presented in Eq. (29) is solved for different sources of uncertainty. As identified in Step 4.1, the uncertainty domain to be tested is composed of the product price and product demand uncertainties. Therefore, 
scenarios were built to test the effect of sources of uncertainty, independently and combined, on the economic objective function, under B1 and B2 conditions. The generated scenarios are the following:

- $\quad \mathrm{Pp}+\mathrm{B} 1$ : uncertainty on the product price, under B1 conditions.

- $\quad \mathrm{Pp}+\mathrm{B} 2$ : uncertainty on the product price, under B2 conditions.

- $\mathrm{D}+\mathrm{B} 1$ : uncertainty on the product demand, under B1 conditions.

- $\mathrm{D}+\mathrm{B} 2$ : uncertainty on the product demand, under B2 conditions.

- $\mathrm{Pp}+\mathrm{D}+\mathrm{B} 1$ : uncertainty on the product demand and product price, under B1 conditions.

- $\quad \mathrm{Pp}+\mathrm{D}+\mathrm{B} 2$ : uncertainty on the product demand and product price, under B2 conditions.

The results obtained by solving the stochastic single-objective optimization for each one of the scenarios above are depicted in Figure 8 and reported in Table 6, and compared to the deterministic solutions.



Figure 8: Results of the solution S1, where the E[NPV] is estimated through SAA for different uncertainty conditions. The triangles represent the deterministic solutions. 
Table 6: Stochastic solutions for the scenarios generated.

\begin{tabular}{|c|c|c|c|}
\hline Scenarios & NPV MM\$ & SI & SC structure \\
\hline $\mathrm{Pp}+\mathrm{B} 1$ & 6011 & 0.0846 & $\begin{array}{l}\text { Plant site locations: Germany, France, The Netherlands, Italy } \\
\text { Suppliers: Germany, France, The Netherlands, Italy } \\
\text { Products: SA, LA } \\
\text { Markets served: } \\
\text { LA - Germany, France, Italy } \\
\text { SA - UK, Spain, Germany, Italy, France } \\
\text { Q }{ }_{\text {glyc }}=2.13 \times 10^{3} \text { kton/year } \\
\text { (same structure as B1 deterministic, see Table 4) }\end{array}$ \\
\hline $\mathrm{D}+\mathrm{B} 1$ & 3286.1 & 0.04459 & $\begin{array}{l}\text { Plant site locations: Germany, France } \\
\text { Suppliers: Germany, France } \\
\text { Products: LA, SA } \\
\text { Markets served: } \\
\text { LA - Germany, France } \\
\text { SA - Germany, France, Spain, UK, Italy } \\
\end{array}$ \\
\hline $\mathrm{Pp}+\mathrm{D}+\mathrm{B} 1$ & 3230.3 & 0.04458 & Same as scenario $(\mathrm{D}+\mathrm{B} 1)$ \\
\hline B1 det. & 6115 & 0.085 & $\begin{array}{l}\text { Plant site locations: Germany, France, The Netherlands, Italy } \\
\text { Suppliers: Germany, France, The Netherlands, Italy } \\
\text { Products: SA, LA } \\
\text { Markets served: } \\
\text { LA - Germany, France, Italy } \\
\text { SA - UK, Spain, Germany, Italy, France } \\
\text { Q }_{\text {glyc }}=2.13 \times 10^{3} \text { kton/year }\end{array}$ \\
\hline $\mathrm{Pp}+\mathrm{B} 2$ & 373.6 & 0.25611 & $\begin{array}{l}\text { Plant site locations: Germany, France, The Netherlands, Italy, } \\
\text { Spain } \\
\text { Suppliers: Germany, France, The Netherlands, Italy, Spain } \\
\text { Products: SA, LA, PHB, Epi } \\
\text { Markets served: } \\
\text { LA - Germany, Italy, Spain } \\
\text { SA - UK, Spain, Germany, Italy, France } \\
\text { PHB - Germany } \\
\text { Epi - Germany, The Netherlands, Belgium, Spain } \\
\text { (same structure as B2 deterministic, see Table 4) }\end{array}$ \\
\hline $\mathrm{D}+\mathrm{B} 2$ & -5493.7 & 0.34542 & $\begin{array}{l}\text { Plant site locations: Germany, France, Netherlands, Spain, Italy } \\
\text { Suppliers: Germany, France, Netherlands, Spain, Italy } \\
\text { Products: LA, SA, PHB, Epi } \\
\text { Markets served: } \\
\text { LA - Italy, Spain } \\
\text { SA - Germany, France, Spain, Italy, UK } \\
\text { PHB - Germany, France } \\
\text { Epi - Germany, The Netherlands, Belgium, Spain, Italy }\end{array}$ \\
\hline $\mathrm{Pp}+\mathrm{D}+\mathrm{B} 2$ & -5525.8 & 0.34542 & Same as scenario (D + B2) \\
\hline B2 det. & 452 & 0.257 & $\begin{array}{l}\text { Plant site locations: Germany, France, The Netherlands, Italy, } \\
\text { Spain } \\
\text { Suppliers: Germany, France, The Netherlands, Italy, Spain } \\
\text { Products: SA, LA, PHB, Epi } \\
\text { Markets served: } \\
\text { LA - Germany, Italy, Spain } \\
\text { SA - UK, Spain, Germany, Italy, France } \\
\text { PHB - Germany } \\
\text { Epi - Germany, The Netherlands, Belgium, Spain }\end{array}$ \\
\hline
\end{tabular}


The results presented in Figure 8 and Table 6 have shown that the demand has a high impact on the objective function (NPV), and that the product price uncertainty further decreases the NPV of the project. In the case of the B1 conditions, since the model has an additional degree of freedom compared to scenario B2 conditions, the model is flexible enough to adjust the production in face of uncertainty. In the present case, the demand uncertainty leads to a decrease in the production and accordingly a decrease in the environmental impact. Under B2 conditions, the NPV drops significantly when compared to the deterministic counterpart, because there is no flexibility to decrease the inflow of glycerol. Thus, under demand uncertainty, the optimal NPV is obtained when increasing the production of PHB and correspondingly decreasing the production of SA and LA. This is accompanied by an increase in the environmental impact since the production of PHB is a heavier consumer of utilities at the separation and purification stages than the other products. Furthermore, it can be observed that following the realistic scenario when both sources of uncertainty play a role in the market environment (scenario Pp $+\mathrm{D}+\mathrm{B} 1$ and B2 in Table 6 and Figure 11), the NPV of the project decreases, for both B1 and B2. All in all, the deterministic solutions dominate the stochastic solutions, presenting better economic performance. Therefore, it can be concluded that it is critical to not overlook the presence of inherent uncertainties.

In summary, since the combination of uncertainties in price and demand composes a realistic scenario, which leads to a high impact on the model outcomes, this scenario will be analyzed in detail in the next solution approach, S2.

\section{Solution S2 - SC structure mapping and analysis}

In this step, a deterministic optimization problem corresponding to the solution of the problem formulated in Eq. (22), is solved for each one of the scenarios generated by Monte Carlo sampling performed in Step 4.1. Immediate consequences of the data uncertainty on the facets of the decision-making problem are statistically analyzed. The result is composed of a distribution of 50 optimal (NS) NPV and SI values (points) that are mapped and statically analyzed. Every point solution of sample $s$ is characterized by a SC structure, reflecting design and planning decisions. Moreover, as to decrease the computational effort (by reducing the number of equations), the SI calculation is reduced to include solely two of the categories of impact. To this end, a significance test was performed with the purpose of pinpointing which are the two categories that weigh more in the single indicator (SI) for both B1 and B2 deterministic cases. Therefore, the scenario where both the product price and the product demand are sources of uncertainty is here analyzed in more detail through S2, under conditions corresponding to scenarios B1 and B2. The results regarding B1 are described in detail below. 
In Figure 9 the optimal NPV obtained for the optimization problem resulting from each Monte Carlo sample is presented. Comparing to the B1 base case (deterministic) it is observed that the probability of NPV being lower than the deterministic B1 is 98\% (Figure 10), with an average (3.28x103MM $\$$ ) that corresponds to $46 \%$ of the deterministic NPV (see Table 4). This is due to the adjustment of the planning decisions to the uncertainty realization characterizing the scenarios $s$, where the market demand instability and reduced product price, leads to a lower optimal inflow of glycerol converted (1120 kton/y), when compared to the optimal nominal inflow identified in the B1 base case (2126 kton/y) as presented in Figure 9. Also, as depicted in Figures 9 and 10, the maximum NPV reached is approximately $80 \%$ higher than the minimum NPV reported. This results from the increase in the product market price when moving from left to right in Figure 9, which also justifies the slight change in the markets served. Furthermore, as above-mentioned, there is a significant difference between the expected deterministic NPV and the stochastic solution, thus carrying economic risk. Therefore, it is critical to consider the inherent presence of uncertainties and its potential effect on the optimal SC structure and corresponding inflow of crude glycerol.

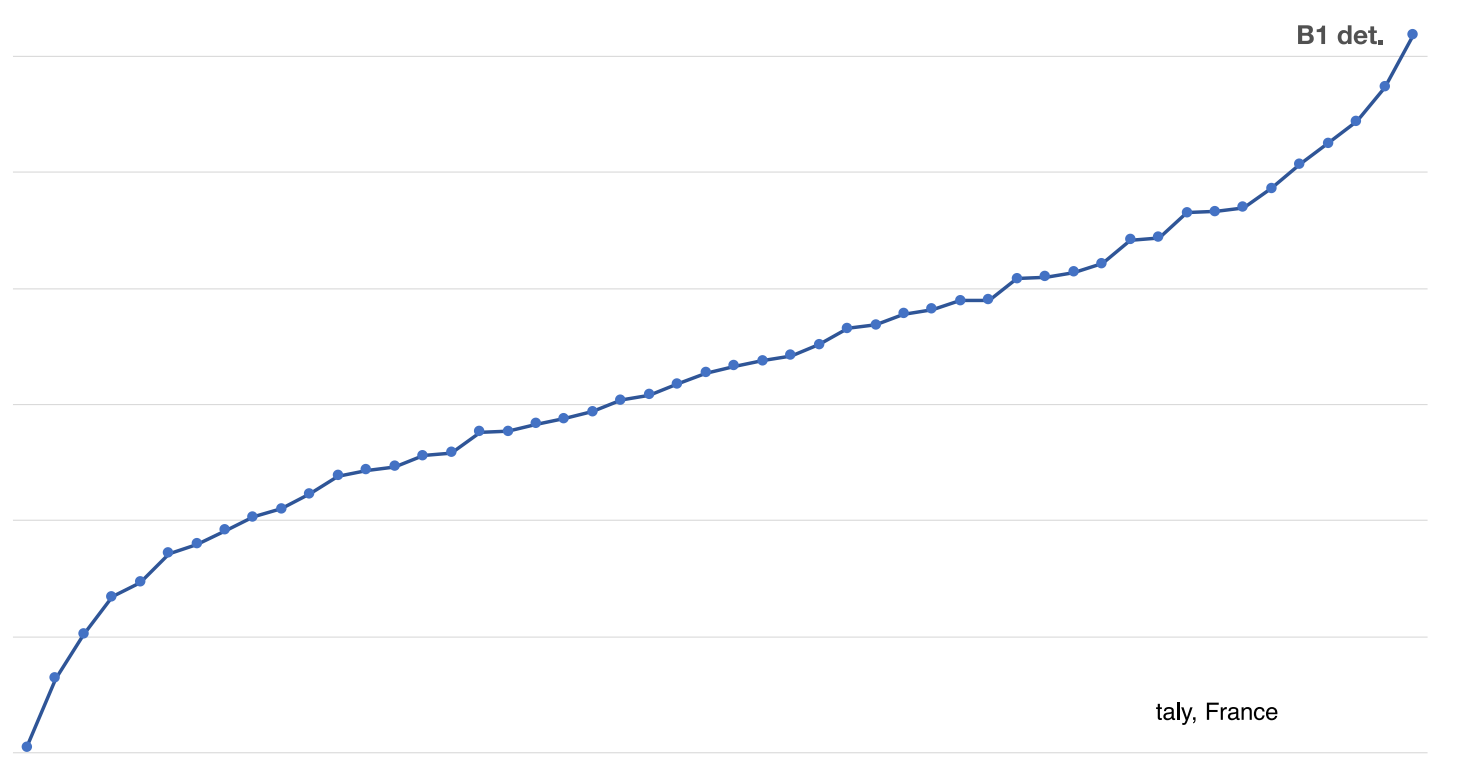

Figure 9: NPV variation for all scenarios along with the highlighting of some significant SC structures and their characteristics for $\mathbf{B} 1$ conditions. 


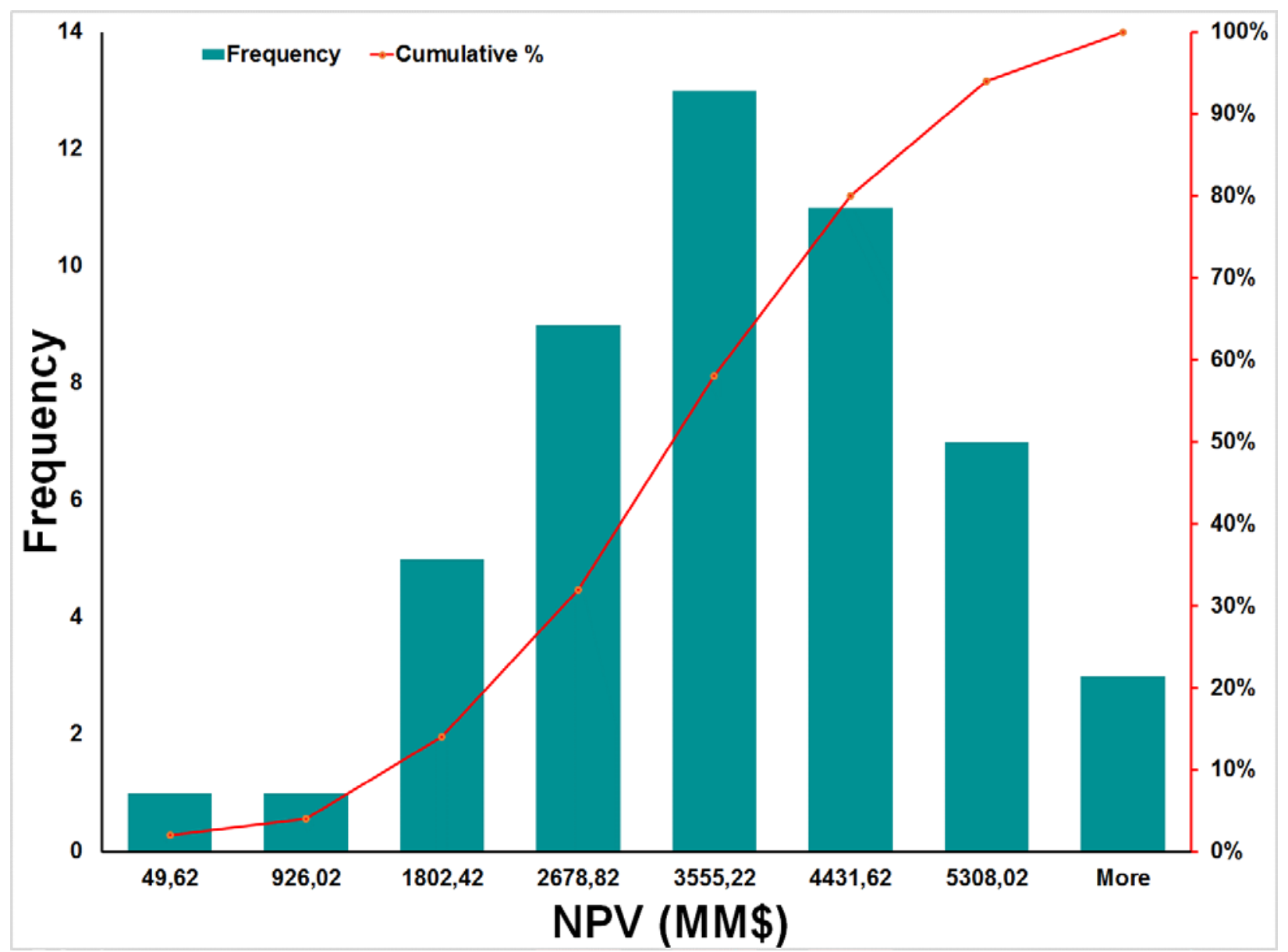

Figure 10: Cumulative probability distribution of the NPV and frequency of selection of the corresponding SC structures for B1 conditions.

The alternative that presents a high probability of having a positive NPV and thus having the project being approved, even under market uncertainty, is scenario B1. This is due to the fact that B1 has an extra degree of freedom when compared to B2, where B1 is capable of adjusting the inflow of glycerol, and thus the production, according to the market environment, which leads to positive NPV's. In contrast, the SC structures obtained under B2 conditions are economically unfeasible for all uncertainty realizations (see Figure SM5 in the supplementary material), as expected from the results obtained by applying solution approach S1.

Therefore, a more detailed analysis was performed into the topology of the obtained solutions under B1 conditions. The main characteristics and the frequency of selection are presented in Table 7. It is observed that the topology-1 (Top-1) is selected in $96 \%$ of the events, which is characterized by having the plants located in Germany and France for the production of SA and LA. These production plants are also characterized by the maximum level of production capacity ( $q=3$ ), which is stable in $90 \%$ of the uncertainty realizations (see Figure SM7 in supplementary material). Thus, Top-1 is considered to be a robust solution 
under the stochastic conditions. This conclusion is further supported by the results obtained through solution approach S1.

Table 7: SC topology and corresponding frequency of selection.

\begin{tabular}{|c|c|c|c|c|l|}
\hline Topologies & $\begin{array}{c}\text { Frequency } \\
\text { of selection }\end{array}$ & Technology & Suppliers & $\begin{array}{c}\text { Plant site } \\
\text { locations }\end{array}$ & \multicolumn{1}{c|}{ Markets } \\
\hline Top-1 & $96 \%$ & $\begin{array}{c}\text { Glycerol } \\
\text { conversion to } \\
\text { SA and LA } \\
\text { (kC3 \& ksp3 in } \\
\text { Table 2) (q=3) }\end{array}$ & $\begin{array}{c}\text { Germany, } \\
\text { France }\end{array}$ & $\begin{array}{c}\text { Germany, } \\
\text { France }\end{array}$ & $\begin{array}{l}\text { Germany: } \\
\text { LA - Germany } \\
\text { SA - UK; Germany, Italy; } \\
\text { France: } \\
\text { LA - France } \\
\text { SA - Spain, France, Germany, Italy }\end{array}$ \\
\hline Top-2 & $4 \%$ & $\begin{array}{c}\text { Glycerol } \\
\text { conversion to } \\
\text { SA and LA } \\
\text { (kC3 \& ksp3 in } \\
\text { Table 2) (q=3) }\end{array}$ & $\begin{array}{c}\text { Germany, The } \\
\text { Netherlands }\end{array}$ & $\begin{array}{l}\text { Germany, The } \\
\text { Netherlands }\end{array}$ & $\begin{array}{l}\text { Germany: } \\
\text { LA - Germany, France } \\
\text { SA - Germany, France, Italy; } \\
\text { The Netherlands: } \\
\text { LA - Germany } \\
\text { SA - UK, Spain, France, Germany }\end{array}$ \\
\hline
\end{tabular}

Overall, this theoretical analysis performed on the glycerol-based biorefinery supply chain (based on the SC description provided in Step 1 of the framework), suggested that an economically feasible project could be obtained based upon a decentralized setup of plants located in Germany and France for the production of SA and LA. This corresponds to an expected NPV of approximately $3.28 \times 10^{3} \mathrm{MM} \$$, under stochastic conditions for the conversion of $2.13 \times 10^{3} \mathrm{kton}$ of glycerol/year.

Furthermore, it is important to note that the stress test performed on the prices of LA and SA, where these crash to $50 \%$ of their original value, has demonstrated that this might have drastic consequences on the feasibility of the project, potentially leading to a negative NPV (see Table 5). This further emphasizes the need to better understand the correlation between the product price patterns and demand, considering the increase or decrease of product availability in the market. Hence, more investigation into the dynamics between the availability of a product in the market and its consequent price is recommended as future work, by, for example, applying the recognized theory of supply and demand, as the first step towards understanding how market prices are defined and how they shape production and consumption decisions.

\section{Solution S3 - stochastic multi(bi)-objective optimization}

The aim of this solution approach, as formulated in Eq. (30), is to identify the existing tradeoffs between the economic (NPV) and environmental (SI) performances, in this way providing control over the variability of the SI. The first step is to estimate the lower bound and the upper bound for the SI. The lower bound ( $\varepsilon^{\mathrm{min}}$ ) is obtained by solving Eq. (31). The SI upper bound $\left(\varepsilon^{\max }\right)$ is obtained by solving Eq. (32), where SI corresponds to the optimal NPV obtained for the B1 conditions under product price and product demand 
uncertainties. The optimization problem, as stated in Eq. (30) was then solved for several instances between $\varepsilon^{\min }$ and $\varepsilon^{\max }$ values, leading to the Pareto front of solutions portrayed in Figure 11.

All the optimal solutions that take into account the NPV and SI objectives lie on the Pareto curve. Therefore, the solutions above the curve in Figure 11 are suboptimal solutions, and all solutions below this curve are infeasible. The trend of this Pareto curve reveals a clear tradeoff, where a gain in NPV leads to a lower environmental performance. This is due to the fact that NPV is increased when the inflow of glycerol and corresponding production is raised. The increase in the production leads to a higher environmental burden since the production emissions are augmented. As can be observed in Figure 11, the minimum environmental burden is obtained for the conversion of $8 \mathrm{kton} / \mathrm{y}$, producing $5 \mathrm{kton} / \mathrm{y}$ of epichlorohydrin, with NPV of -124 MM\$. The stochastic maximum leads to the production SA and LA, by consuming $1121 \mathrm{kton} / \mathrm{y}$ with NPV of 3230 MM\$. Additionally, the deterministic Pareto front is also shown. As expected, the NPV of the deterministic set of solutions is slightly higher than under uncertainty. This is especially noticed between the maximum NPV achievable through deterministic and uncertainty conditions, where the deterministic solution dominates the stochastic solution by approximately $90 \%$.

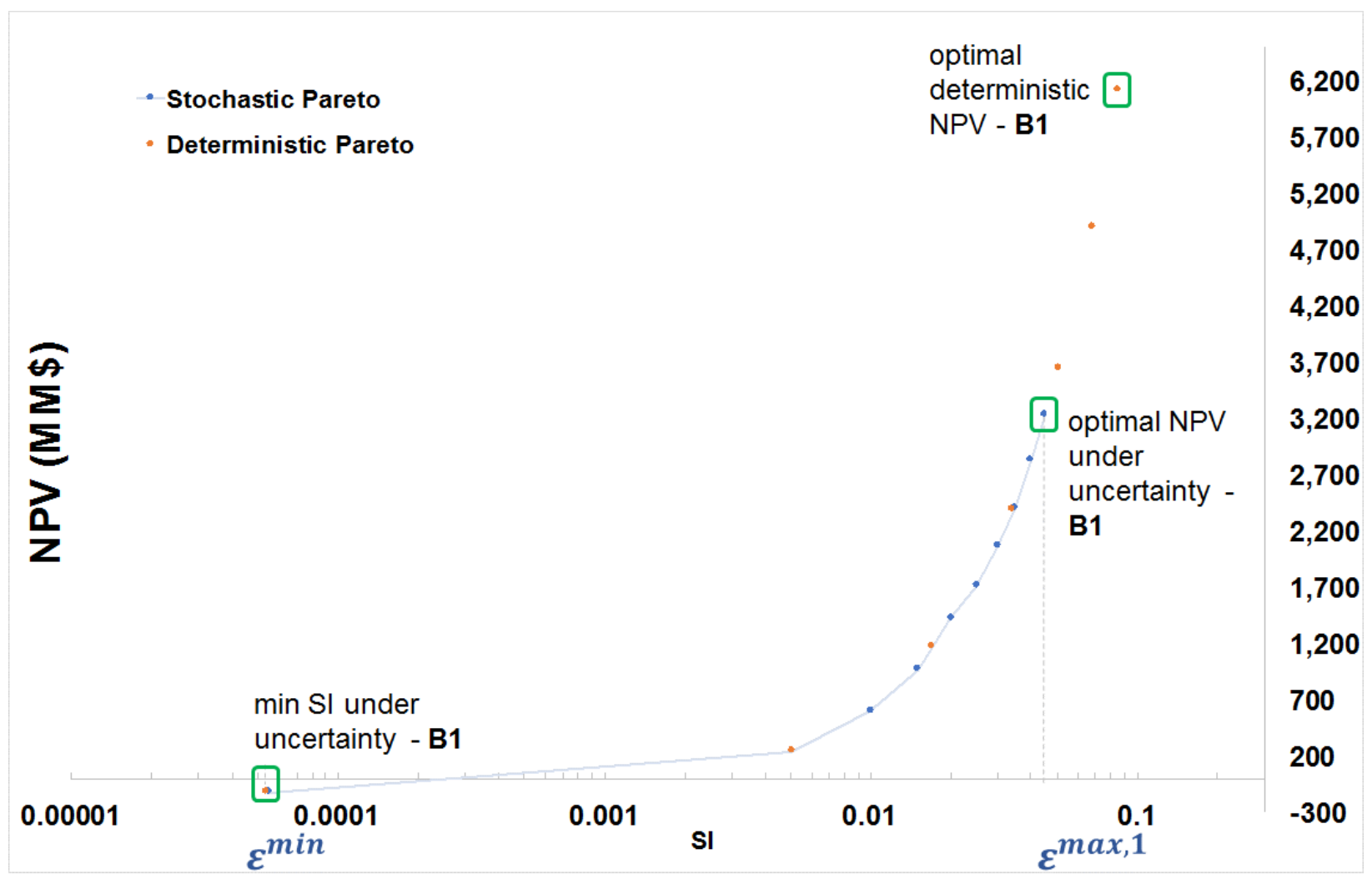

Figure 11: Pareto of optimal solutions, highlighting the trade-offs observed between the NPV and SI under demand and product price uncertainties. $\varepsilon^{\max , 1}$ represents the maximum value of SI obtained by maximizing the NPV of the supply chain, under B1 conditions. $\varepsilon^{\min }$ is the SI corresponding to the minimum SI obtainable under B1 conditions. 
Furthermore, an additional analysis was carried out in order to understand the variation of the NPV and the SI when the optimization problem is moving from the B1 conditions to B2 conditions, and the results of this analysis are presented in Figure 12. The $\varepsilon^{\max , 2}$ is the SI corresponding to the maximum NPV obtainable under stochastic B2 conditions, where the problem is constrained to convert the total glycerol available in Europe in a given year.



Figure 12: Set of solutions corresponding to the monitoring of the environmental impact, under product price and product demand uncertainty. $\varepsilon^{\max , 1}$ represents the maximum value of SI obtained by maximizing the NPV of the supply chain, under B1 conditions. $\varepsilon^{\text {max,2}}$ stands for the SI corresponding to the maximum NPV obtainable under B2 conditions.

As observed in Figure 12, there is a strong trend when moving from $\varepsilon^{\max , 1}$ to $\varepsilon^{\max , 2}$, where the NPV of the optimal SC structure is declining along with an increase in the SI values. This is due to the fact that the amount of glycerol converted is increasing, thus moving away from the optimal value corresponding to the $\varepsilon^{\max , 1}$. This is accompanied by significant changes in the optimal SC structure given by the increase in the SA and LA production, along with the production of Epi and PHB, whose production is increased until all glycerol is converted (optimal SC structure at B2 conditions).

Moreover, as expected from previous solutions S1 and S2, there is a significant reduction of the NPV when shifting from the deterministic to the stochastic solution, where the deterministic solution is always depicted above the stochastic solutions. This is a very clear argument proving the importance of considering the inherent presence of uncertainties, especially regarding the market-related uncertain circumstances. 


\section{Conclusions}

A novel decision-making framework to holistically optimize the design and planning of the glycerol-based biorefinery supply chains under uncertainties is proposed in this work. The set of optimal decisions regarding design, operation and strategy provided by the multi-layered framework, includes supply chain network layout, facility location and sizing, technology selection, yearly production planning and cross-country logistics. The framework was demonstrated on a superstructure build based on 5 possible plant site locations, 7 available conversion technologies, 7 available separation and purification technologies, 7 unique products, and 5 markets were identified for each one of the products. The results have shown that: (i) market uncertainties highly affect the economic and environmental performances of the optimal SC structure when compared to the nominal threshold; (ii) under market uncertainty, the economic performance is maximized for the case where the SC is flexible and not constrained to convert all glycerol available (scenario B1); (iii) the set of SC structures obtained under stochastic conditions is robust, where, with $96 \%$ frequency of selection, the optimal SC structure is characterized by a decentralized production of SA and LA in the production plants located in Germany and France, despite given future uncertainties; and, (iv) the multi-objective optimization results in Pareto-optimal curves that reveal the tradeoff between the economic and environmental dimensions of the glycerol-based biorefinery supply chains.

All in all, the proposed framework aims at being a decision-making tool through supply chain optimization, leading to the identification of the optimal design and planning decisions for the development of environmentally conscious biorefinery supply chains. Furthermore, despite the fact that it has been developed for the optimal design and planning of glycerol-based biorefinery supply chains, the proposed framework is flexible and adaptable to other biorefineries that are similar in nature.

\section{Acknowledgements}

We thank the Reneseng Project, an EU FP7 Marie Curie Initial Training Network (ITN), Grant agreement 607415 , for the financial support of the research work. Furthermore, the financial support from Fundação para a Ciência e a Tecnologia (under Grant No. SFRH/BSAB/128453/2017) is also acknowledged.

\section{Supporting Information}

This information is available free of charge via the Internet at http://pubs.acs.org/. 


\section{Nomenclature}

\section{Subscript indices}

\begin{tabular}{l|l}
$i$ & Components
\end{tabular}

k Technologies

$x \quad$ Plant site locations

$t \quad$ Time periods

\begin{tabular}{l|l}
$r$ & Reactions
\end{tabular}

$q \quad$ Capacity levels

m Final markets

z. Suppliers

\begin{tabular}{c|l}
\multicolumn{2}{ll}{ Sets } \\
\hline$I$ & Set of all components $i$ \\
$I_{p}$ & Set of components $i$ that are final products \\
$I_{r m}$ & Set of components $i$ that are raw materials \\
$I_{u t}$ & Set of components $i$ that are utilities and/or chemicals/solvents \\
$I_{r}$ & Set of components $i$ that are reactants \\
$K$ & Set of all technologies $k$ \\
$K_{G P}$ & Set of technologies $k$ used for the purification of raw materials
\end{tabular}


Set of technologies $k$ used for the conversion of raw materials to final products $i \in I_{p}$ Set of technologies $k$ used for the separation and purification of final products $i \in I_{p}$ Set of plant site locations $x$

Set of time periods $t$

Set of reactions $r$

Set of capacity levels $q$

Set of final markets $m$

Set of all suppliers $z$

\section{Parameters}

The parameters are grouped by type/function and are presented in order of appearance in the constraints, objective function and auxiliary variables.

\begin{tabular}{c|l} 
Technology & \\
\hline$\emptyset_{i, z, t}$ & Raw materials $i$ available from supplier $z$ in time period $t$ \\
$\alpha_{i, k}$ & Specific utility consumption of $i$ in $k$ \\
$\theta_{i, k, r}$ & Conversion of reactant $i$ in technology $k$ where $r$ occurs \\
$\gamma_{i, k, r}$ & Reaction stoichiometry for every component $i$ in technology $k$ and reaction $r$ \\
$\mu_{i, k}$ & Fraction of chemicals/solvents mixed with process stream of $i$ in technology $k$ \\
$S W_{i, k k}$ & Fraction of $i$ that is separated as waste in $k$ \\
\hline
\end{tabular}

Technology capacity and cost

\begin{tabular}{c|l}
$H_{k, q}^{\min }$ & Minimum capacity for each capacity level $q$ for technology $k$ \\
$H_{k, q}^{\max }$ & Maximum capacity for each capacity level $q$ for technology $k$ \\
$s_{\text {sop }} e_{k, q, x}$ & Linearization constant for technology $k$ and interval $q$ \\
$b_{k, q, x}$ & Intercept value for the linearized interval $q$ for technology $k$ \\
$c_{k}^{\text {max }}$ & Maximum cost of technology $k$ \\
$w c_{t}$ & Operating supplies cost at time period $t$ \\
$m s_{t}$ & Maintenance cost at time period $t$ \\
$\lambda_{t}$ & Depreciation rate of the investment per time period $t$
\end{tabular}

\section{Transportation}

\begin{tabular}{l|l}
$D_{p, m, t}$ & Demand of product $p$ in market $\mathrm{m}$ in time period $t$
\end{tabular}

$L \quad$ Total load of transport mode per trip travelled

$p R \quad$ Cost of rail freight per ton.km

$d_{x, m} \quad$ Distance of market $\mathrm{m}$ from plant site location $\mathrm{x}$

\section{Cost related parameters \\ $p R M \quad$ Price of raw materials $i \in I_{r m}$ \\ $p U T_{i} \quad$ Price of utilities per component $i \in I_{u t}$ \\ $p S t_{p} \quad$ Storage price per final product $i \in I_{p}$ \\ $p P_{i, s} \quad$ Price of final product $i \in I_{p}$ for scenario $s$ \\ $\omega$ \\ Interest rate $(\%)$ \\ $\varphi$ \\ Tax rate $(\%)$}

\begin{tabular}{c|l}
$L C A$ related parameters \\
\hline$C F_{i, c}$ & Characterization factor to convert inventory of component $i$ into impact category $c$ \\
$w_{c}$ & Weighting factor for impact category $c$ \\
$\lambda_{c s_{i, k}}$ & Emissions of component $i$ linked to the separation and purification per unit of reference component flow in \\
$\lambda_{s l_{i, k}}$ & technology $k$ \\
& Emissions of component $i$ linked to the usage of solvents / chemicals/ catalysts per unit of reference component \\
\hline
\end{tabular}




\section{Decision variables}

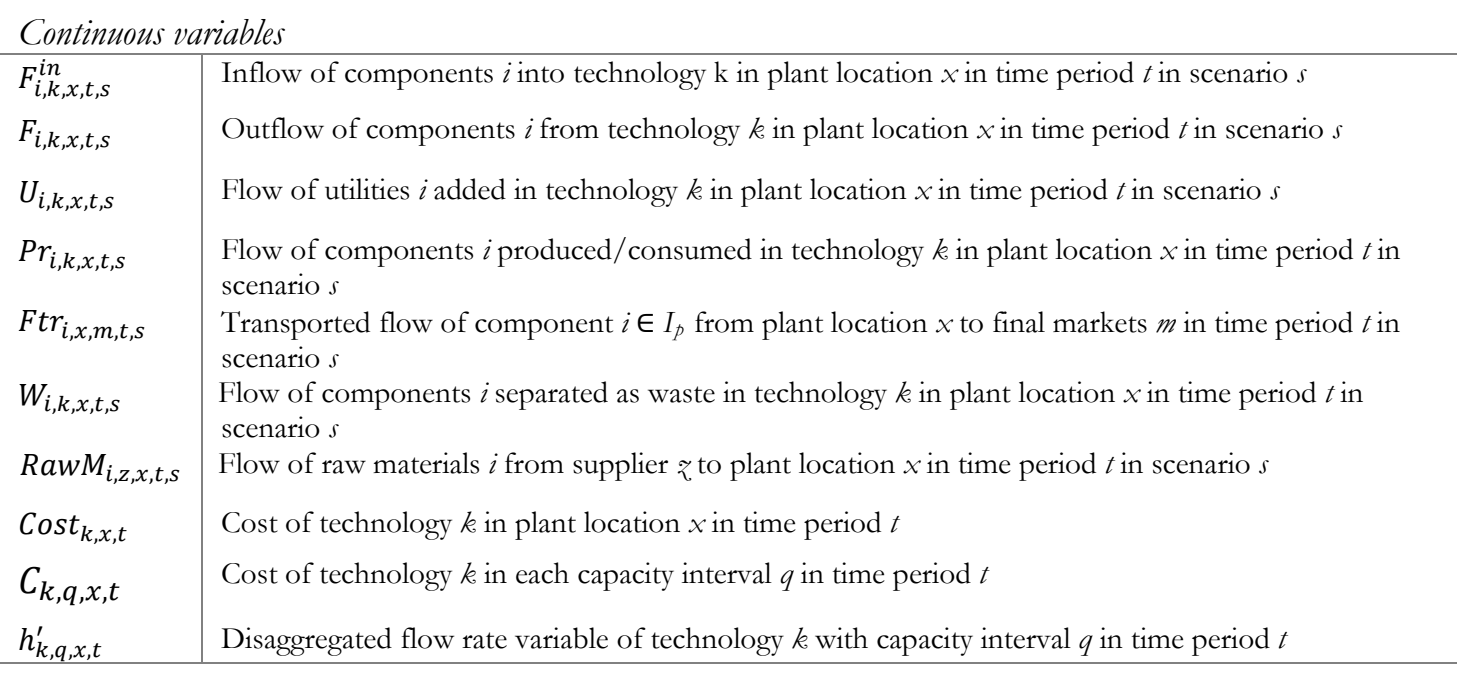

\section{Integer variables}

\begin{tabular}{c|l}
\hline$T_{x, m, t, s}$ & Number of trips performed by truck from plant site location $x$ to markets $m$ in time period t in scenario $s$ \\
\hline$T_{z, x, t, s}$ & Number of trips performed by truck from supplier $z$ to plant site location $x$ in time period $t$ in scenario $s$ \\
\hline
\end{tabular}

Binary variables

\begin{tabular}{c|l}
\multicolumn{1}{c}{ Binary variables } \\
\hline$y_{\boldsymbol{k}, \boldsymbol{q}, \boldsymbol{x}, \boldsymbol{t}}$ & \multicolumn{1}{c}{ if technology $k$ with capacity $q$ is installed in location $x$ in time period $t$} \\
\multicolumn{3}{l}{ Auxiliary variables for the objective function } \\
\hline$N P V$ & Net Present Value \\
$C F_{t, s}$ & Cash flow in time period $t$ in scenario $s$ \\
$N E_{t, s}$ & Net earnings in time period $t$ in scenario $s$ \\
$F C I_{k, x, t}$ & Fixed capital investment of technology $k$ in plant location $x$ and time period $t$ \\
$C D_{t}, s$ & Capital depreciation in time period $t$ in scenario $s$ \\
$b$ & Representative of all 1 st stage variables \\
$b_{s}$ & Representative of all $2^{\text {nd }}$ stage variables \\
$S_{c}$ & Impact category $c$ \\
$S I$ & Single Indicator for environmental assessment
\end{tabular}




\section{References}

1. Demirbas A, Demirbas MF. Algae Energy-Algae as a New Source of Biodiesel. Springer; 2010. 199 p.

2. Dansereau LP, El-Halwagi M, Chambost V, Stuart P. Methodology for biorefinery portfolio assessment using supply-chain fundamentals of bioproducts. Biofuels Bioprod Biorefining-Biofpr. 2014;8(5):716-727.

3. Yue D, You F, Snyder SW. Biomass-to-bioenergy and biofuel supply chain optimization: Overview, key issues and challenges. Comput Chem Eng [Internet]. 2014 Jul [cited 2014 Jul 11];66:36-56. Available from: http://linkinghub.elsevier.com/retrieve/pii/S0098135413003670

4. Golden JS, Handfield R, Daystar J, Morrison B, McConnell E. An Economic Impact Analysis of the U.S. Biobased Products Industry. 2016.

5. Gargalo CL, Carvalho A, Gernaey K V., Sin G. Supply Chain Optimization of Integrated Glycerol Biorefinery: GlyThink Model Development and Application. Ind Eng Chem Res [Internet]. 2017 May 30 [cited 2017 Jun 5];acs.iecr.7b00908. Available from: http://pubs.acs.org/doi/abs/10.1021/acs.iecr.7b00908

6. Gargalo CL, Cheali P, Posada JA, Gernaey K V., Sin G. Economic Risk Assessment of Early Stage Designs for Glycerol Valorization in Biorefinery Concepts. Ind Eng Chem Res [Internet]. 2016 Jun 22 [cited 2016 Nov 17];55(24):6801-14. Available from: http://pubs.acs.org/doi/abs/10.1021/acs.iecr.5b04593

7. Svensson E, Eriksson K, Wik T. Reasons to apply operability analysis in the design of integrated biorefineries. Biofuels, Bioprod Biorefining [Internet]. 2015 Mar 24 [cited 2016 Nov 21];9(2):147-57. Available from: http://doi.wiley.com/10.1002/bbb.1530

8. Gebreslassie BH, Yao Y, You F. Design under uncertainty of hydrocarbon biorefinery supply chains: Multiobjective stochastic programming models, decomposition algorithm, and a Comparison between CVaR and downside risk. AIChE J [Internet]. 2012 Jul [cited 2016 Dec 19];58(7):2155-79. Available from: http://doi.wiley.com/10.1002/aic.13844

9. Yue D, You F. Optimal supply chain design and operations under multi-scale uncertainties: Nested stochastic robust optimization modeling framework and solution algorithm. AIChE J [Internet]. 2016 Sep [cited 2016 Dec 19];62(9):3041-55. Available from: http://doi.wiley.com/10.1002/aic.15255

10. Halemane KP, Grossmann IE. Optimal process design under uncertainty. AIChE J [Internet]. 1983 May [cited 2016 Dec 19];29(3):425-33. Available from: http://doi.wiley.com/10.1002/aic.690290312

11. Bairamzadeh S, Pishvaee MS, Saidi-Mehrabad M. Multiobjective robust possibilistic programming 
approach to sustainable bioethanol supply chain design under multiple uncertainties. Ind Eng Chem Res. ACS Publications; 2015;55(1):237-56.

12. Gong J, Garcia DJ, You F. Unraveling Optimal Biomass Processing Routes from Bioconversion Product and Process Networks under Uncertainty: An Adaptive Robust Optimization Approach. ACS Sustain Chem Eng [Internet]. 2016 Jun 6 [cited 2016 Dec 19];4(6):3160-73. Available from: http://pubs.acs.org/doi/abs/10.1021/acssuschemeng.6b00188

13. Gupta A, Maranas CD. Managing demand uncertainty in supply chain planning. Comput Chem Eng. 2003;27(8-9):1219-27.

14. Gargalo CL, Cheali P, Posada JA, Carvalho A, Gernaey K V., Sin G. Assessing the environmental sustainability of early stage design for bioprocesses under uncertainties: An analysis of glycerol bioconversion. J Clean Prod [Internet]. 2016 Dec [cited 2017 Apr 19];139:1245-60. Available from: http://linkinghub.elsevier.com/retrieve/pii/S0959652616313208

15. You F, Graziano DJ, Snyder SW. Optimal Design of Sustainable Cellulosic Biofuel Supply Chains : Multiobjective Optimization Coupled with Life Cycle Assessment and Input - Output Analysis. 2012;58(4).

16. Awudu I, Zhang J. Uncertainties and sustainability concepts in biofuel supply chain management: A review. Renew Sustain Energy Rev [Internet]. Elsevier Ltd; 2012;16(2):1359-68. Available from: http://dx.doi.org/10.1016/j.rser.2011.10.016

17. Kim J, Realff MJ, Lee JH, Whittaker C, Furtner L. Design of biomass processing network for biofuel production using an MILP model. Biomass and Bioenergy [Internet]. Elsevier Ltd; 2011;35(2):853-71. Available from: http://dx.doi.org/10.1016/j.biombioe.2010.11.008

18. Kim J, Realff MJ, Lee JH. Optimal design and global sensitivity analysis of biomass supply chain networks for biofuels under uncertainty. Comput Chem Eng. Elsevier; 2011;35(9):1738-51.

19. Kostin AM, Guillén-Gosálbez G, Mele FD, Bagajewicz MJ, Jiménez L. Design and planning of infrastructures for bioethanol and sugar production under demand uncertainty. Chem Eng Res Des [Internet]. 2012 Mar [cited 2016 Dec 18];90(3):359-76. Available from: http:/ /linkinghub.elsevier.com/retrieve/pii/S0263876211002656

20. McLean K, Li X. Robust scenario formulations for strategic supply chain optimization under uncertainty. Ind Eng Chem Res. ACS Publications; 2013;52(16):5721-34.

21. Awudu I, Zhang J. Stochastic production planning for a biofuel supply chain under demand and price uncertainties. Appl Energy [Internet]. 2013 Mar [cited 2017 Jan 27];103:189-96. Available from: 
http://linkinghub.elsevier.com/retrieve/pii/S0306261912006666

22. Tong K, Gong J, Yue D, You F. Stochastic programming approach to optimal design and operations of integrated hydrocarbon biofuel and petroleum supply chains. ACS Sustain Chem Eng. ACS Publications; 2013;2(1):49-61.

23. Tong K, Gleeson MJ, Rong G, You F. Optimal design of advanced drop-in hydrocarbon biofuel supply chain integrating with existing petroleum refineries under uncertainty. biomass and bioenergy. Elsevier; 2014;60:108-20.

24. Kasivisvanathan H, Ubando AT, Ng DKS, Tan RR. Robust optimization for process synthesis and design of multifunctional energy systems with uncertainties. Ind Eng Chem Res. ACS Publications; 2014;53(8):3196-209.

25. Geraili A, Romagnoli JA. A multiobjective optimization framework for design of integrated biorefineries under uncertainty. AIChE J [Internet]. 2015 Oct [cited 2016 Oct 27];61(10):3208-22. Available from: http://doi.wiley.com/10.1002/aic.14849

26. Geraili A, Salas S, Romagnoli JA. A Decision Support Tool for Optimal Design of Integrated Biorefineries under Strategic and Operational Level Uncertainties. Ind Eng Chem Res [Internet]. 2016


http://pubs.acs.org/doi/abs/10.1021/acs.iecr.5b04003

27. Giarola S, Shah N, Bezzo F. A comprehensive approach to the design of ethanol supply chains including carbon trading effects. Bioresour Technol. Elsevier; 2012;107:175-85.

28. Giarola S, Bezzo F, Shah N. A risk management approach to the economic and environmental strategic design of ethanol supply chains. Biomass and Bioenergy. Elsevier; 2013;58:31-51.

29. Santibañez-Aguilar JE, Morales-Rodriguez R, González-Campos JB, Ponce-Ortega JM. Stochastic design of biorefinery supply chains considering economic and environmental objectives. J Clean Prod. Elsevier; 2016;136:224-45.

30. Ness B, Urbel-Piirsalu E, Anderberg S, Olsson L. Categorising tools for sustainability assessment. Ecol Econ [Internet]. 2007 Jan [cited 2017 Apr 29];60(3):498-508. Available from: http://linkinghub.elsevier.com/retrieve/pii/S0921800906003636

31. European Commission. Communication from the Commission to the Council and the European Parliament - Integrated Product Policy - Building on Environmental Life-cycle Thinking. 2003.

32. Mota B, Gomes MI, Carvalho A, Barbosa-Povoa AP. Towards supply chain sustainability: Economic, environmental and social design and planning. J Clean Prod [Internet]. Elsevier Ltd; 2015;105:14-27. 
Available from: http://dx.doi.org/10.1016/j.jclepro.2014.07.052

33. ISO 14044. Environmental Management e Life Cycle Assessment e Principles and Framework. 2006.

34. Carvalho A, Mimoso AF, Mendes AN, Matos HA. From a literature review to a framework for environmental process impact assessment index. J Clean Prod [Internet]. 2014 Feb [cited 2017 Apr 29];64:36-62. Available from: http://linkinghub.elsevier.com/retrieve/pii/S0959652613005325

35. Frota Neto JQ, Bloemhof-Ruwaard JM, van Nunen JAEE, van Heck E. Designing and evaluating sustainable logistics networks. Int J Prod Econ [Internet]. 2008 Feb [cited 2017 Apr 29];111(2):195208. Available from: http://linkinghub.elsevier.com/retrieve/pii/S0925527307001818

36. Guillén-Gosálbez G, Grossmann IE. Optimal design and planning of sustainable chemical supply chains under uncertainty. AIChE J [Internet]. 2009 Jan [cited 2017 Feb 20];55(1):99-121. Available from: http://doi.wiley.com/10.1002/aic.11662

37. Duque J, Barbosa-Póvoa APFD, Novais AQ. Design and Planning of Sustainable Industrial Networks: Application to a Recovery Network of Residual Products. Ind Eng Chem Res [Internet]. 2010 May 5 [cited 2017 Apr 29];49(9):4230-48. Available from: http://pubs.acs.org/doi/abs/10.1021/ie900940h

38. Pinto-Varela T, Barbosa-Póvoa APFD, Novais AQ. Bi-objective optimization approach to the design and planning of supply chains: Economic versus environmental performances. Comput Chem Eng [Internet]. 2011 Aug [cited 2017 Apr 29];35(8):1454-68. Available from: http://linkinghub.elsevier.com/retrieve/pii/S0098135411000998

39. Zamboni A, Bezzo F, Shah N. Spatially Explicit Static Model for the Strategic Design of Future Bioethanol Production Systems. 2. Multi-Objective Environmental Optimization. Energy \& Fuels [Internet]. 2009 Oct 15 [cited 2017 Apr 29];23(10):5134-43. Available from: http://pubs.acs.org/doi/abs/10.1021/ef9004779

40. Mele FD, Kostin AM, Guillén-Gosálbez G, Jiménez L. Multiobjective Model for More Sustainable Fuel Supply Chains. A Case Study of the Sugar Cane Industry in Argentina. Ind Eng Chem Res [Internet]. 2011 May 4 [cited 2017 Apr 29];50(9):4939-58. Available from: http://pubs.acs.org/doi/abs/10.1021/ie101400g

41. Santibañez-Aguilar JE, González-Campos JB, Ponce-Ortega JM, Serna-González M, El-Halwagi MM. Optimal Planning of a Biomass Conversion System Considering Economic and Environmental Aspects. Ind Eng Chem Res [Internet]. 2011 Jul 20 [cited 2017 Apr 29];50(14):8558-70. Available from: http://pubs.acs.org/doi/abs/10.1021/ie102195g

42. Bernardi A, Giarola S, Bezzo F. Optimizing the economics and the carbon and water footprints of 
bioethanol supply chains. Biofuels, Bioprod Biorefining [Internet]. 2012 Nov [cited 2016 Nov 21];6(6):656-72. Available from: http://doi.wiley.com/10.1002/bbb.1358

43. You F, Tao L, Graziano DJ, Snyder SW. Optimal design of sustainable cellulosic biofuel supply chains: Multiobjective optimization coupled with life cycle assessment and input-output analysis. AIChE J [Internet]. 2012 Apr 28 [cited 2016 Jan 28];58(4):1157-80. Available from: http://doi.wiley.com/10.1002/aic.12637

44. d'Amore F, Bezzo F. Strategic optimisation of biomass-based energy supply chains for sustainable mobility. Comput Chem Eng. 2016;87:68-81.

45. JRC European commission. ILCD Handbook: Recommendations for Life Cycle Impact Assessment in the European context [nternet]. Vasa. 2011. 159 p. Available from: http://lct.jrc.ec.europa.eu/pdfdirectory/ILCD Handbook Recommendations for Life Cycle Impact Assessment in the European context.pdf/at_download/file

46. Goedkoop M, Heijungs R, Huijbregts M, De Schryver A, Struijs J, Van Zelm R. ReCiPe 2008. A life cycle impact Assess method which comprises Harmon Categ Indic midpoint endpoint Lev. 2009;1.

47. Dal Mas M, Giarola S, Zamboni A, Bezzo F. Capacity planning and financial optimization of the bioethanol supply chain under price uncertainty. Comput Aided Chem Eng. Elsevier; 2010;28:97-102.

48. Dal-Mas M, Giarola S, Zamboni A, Bezzo F. Strategic design and investment capacity planning of the ethanol supply chain under price uncertainty. Biomass and Bioenergy. Elsevier; 2011;35(5):2059-71.

49. Chen C-W, Fan Y. Bioethanol supply chain system planning under supply and demand uncertainties. Transp Res Part E Logist Transp Rev. Elsevier; 2012;48(1):150-64.

50. Walther G, Schatka A, Spengler TS. Design of regional production networks for second generation synthetic bio-fuel - A case study in Northern Germany. Eur J Oper Res [Internet]. 2012 Apr [cited 2016 Mar 5];218(1):280-92. Available from: http://linkinghub.elsevier.com/retrieve/pii/S037722171100943X

51. Awudu I, Zhang J. Uncertainties and sustainability concepts in biofuel supply chain management: A review. Renew Sustain Energy Rev [Internet]. 2012 Feb [cited 2016 Mar 5];16(2):1359-68. Available from: http://linkinghub.elsevier.com/retrieve/pii/S1364032111004941

52. Osmani A, Zhang J. Stochastic optimization of a multi-feedstock lignocellulosic-based bioethanol supply chain under multiple uncertainties. Energy. Elsevier; 2013;59:157-72.

53. Foo DCY, Tan RR, Lam HL, Aziz MKA, Klemeš JJ. Robust models for the synthesis of flexible palm oil-based regional bioenergy supply chain. Energy. Elsevier; 2013;55:68-73. 
54. Tong K, You F, Rong G. Robust design and operations of hydrocarbon biofuel supply chain integrating with existing petroleum refineries considering unit cost objective. Comput Chem Eng [Internet]. Elsevier Ltd; 2014;68:128-39. Available from: http://dx.doi.org/10.1016/j.compchemeng.2014.05.003

55. Li Q, Hu G. Supply chain design under uncertainty for advanced biofuel production based on bio-oil gasification. Energy. Elsevier; 2014;74:576-84.

56. Azadeh A, Arani HV, Dashti H. A stochastic programming approach towards optimization of biofuel supply chain. Energy. Elsevier; 2014;76:513-25.

57. Gonela V, Zhang J, Osmani A. Stochastic optimization of sustainable industrial symbiosis based hybrid generation bioethanol supply chains. Comput Ind Eng. Elsevier; 2015;87:40-65.

58. Gonela V, Zhang J, Osmani A, Onyeaghala R. Stochastic optimization of sustainable hybrid generation bioethanol supply chains. Transp Res Part E Logist Transp Rev. Elsevier; 2015;77:1-28.

59. Sharifzadeh M, Garcia MC, Shah N. Supply chain network design and operation: Systematic decisionmaking for centralized, distributed, and mobile biofuel production using mixed integer linear programming (MILP) under uncertainty. Biomass and Bioenergy. Elsevier; 2015;81:401-14.

60. Azadeh A, Arani HV. Biodiesel supply chain optimization via a hybrid system dynamics-mathematical programming approach. Renew Energy. Elsevier; 2016;93:383-403.

61. Mohseni S, Pishvaee MS, Sahebi H. Robust design and planning of microalgae biomass-to-biodiesel supply chain: A case study in Iran. Energy. Elsevier; 2016;111:736-55.

62. Balaman \cSebnem Y\ilmaz, Selim H. Sustainable design of renewable energy supply chains integrated with district heating systems: A fuzzy optimization approach. J Clean Prod. Elsevier; 2016;133:863-85.

63. Gargalo CL, Cheali P, Posada JA, Gernaey K V., Sin G. Economic Risk Assessment of Early Stage Designs for Glycerol Valorization in Biorefinery Concepts. Ind Eng Chem Res [nternet]. 2016 Jun 22 [cited 2016 Oct 16];55(24):6801-14. Available from: http://pubs.acs.org/doi/abs/10.1021/acs.iecr.5b04593

64. Environmental management -- Life cycle assessment -- Principles and framework. Geneva, CH; 2000 Mar.

65. Kim, Sujin and Pasupathy, Raghu and Henderson SG. A guide to sample average approximation. In: Handbook of Simulation Optimization. Springer; 2015. p. 207-43.

66. Ehrgott M. Multicriteria optimization [Internet]. Springer; 2005 [cited 2017 Apr 24]. 323 p. Available 
from:

http:/ / findit.dtu.dk/en/catalog?utf8= $\checkmark$ \&locale=en\&search_field=all_fields\&q=Multicriteria+optim ization+

67. Cavalheiro JMBT, de Almeida MCMD, Grandfils C, da Fonseca MMR. Poly(3-hydroxybutyrate) production by Cupriavidus necator using waste glycerol. Process Biochem [Internet]. 2009 May [cited 2014 Jun 13];44(5):509-15. Available from: http://linkinghub.elsevier.com/retrieve/pii/S1359511309000233

68. Posada J, Cardona C, Gonzalez R. Analysis of the production process of optically pure D-lactic acid from raw glycerol using engineered Escherichia coli strains. Appl Biochem Biotechnol [Internet]. 2012 Feb [cited 2014 Jun 20];166(3):680-99. Available from: http://www.ncbi.nlm.nih.gov/pubmed/22127808

69. Yang F, Hanna M a, Sun R. Value-added uses for crude glycerol--a byproduct of biodiesel production. Biotechnol Biofuels [Internet]. BioMed Central Ltd; 2012 Jan [cited 2014 May 26];5:1-13. Available from:

http:/ / www.pubmedcentral.nih.gov/articlerender.fcgi?artid=3313861\&tool=pmcentrez\&rendertype $=$ abstract

70. Scholten E, Renz T, Thomas J. Continuous cultivation approach for fermentative succinic acid production from crude glycerol by Basfia succiniciproducens DD1. Biotechnol Lett [Internet]. 2009 Dec [cited 2016 Feb 26];31(12):1947-51. Available from: http://www.ncbi.nlm.nih.gov/pubmed/19705071

71. Molel E, Phillips H, Smith A. 1, 3-Propanediol from Crude Glycerol. Pennsylvania; 2015.

72. Zeng A-P, Biebl H. Bulk chemicals from biotechnology: the case of 1,3-propanediol production and the new trends. Adv Biochem Eng Biotechnol. 2002;74:239-59.

73. Nakamura CE, Whited GM. Metabolic engineering for the microbial production of 1,3-propanediol. Curr Opin Biotechnol [Internet]. 2003 Oct [cited 2016 Jan 12];14(5):454-9. Available from: http://linkinghub.elsevier.com/retrieve/pii/S0958166903001265

74. Bricker ML, LE L. Methods for Converting Glycerol to Propanol [Internet]. United States; 08101807 B2, 2012. Available from: http://www.google.com/patents/US8101807

75. Cabaniss S, Park D, Silvinsky M, Wagoner J, Chen D, You F. Design G2 [Internet]. 2014. Available from: https://processdesign.mccormick.northwestern.edu/index.php/Design_G2

76. Liu L, Ye XP, Bozell JJ. A comparative review of petroleum-based and bio-based acrolein production. 
ChemSusChem [Internet]. 2012 Jul [cited 2016 Feb 5];5(7):1162-80. Available from: http://www.ncbi.nlm.nih.gov/pubmed/22492577

77. Almena A, Martín M. Technoeconomic Analysis of the Production of Epichlorohydrin from Glycerol. Ind Eng Chem Res [Internet]. 2015;acs.iecr.5b02555. Available from: http://pubs.acs.org/doi/10.1021/acs.iecr.5b02555

78. Tecnon-Orbichem. Chem-Net facts: Epychlorohydrin. 2013.

79. Ruiz-Femenia R, Guillén-Gosálbez G, Jiménez L, Caballero JA. Multi-objective optimization of environmentally conscious chemical supply chains under demand uncertainty. Chem Eng Sci [Internet]. 2013 May [cited 2017 May 1];95:1-11. Available from: http://linkinghub.elsevier.com/retrieve/pii/S0009250913001644

80. You F, Grossmann IE. Design of responsive supply chains under demand uncertainty. Comput Chem Eng [Internet]. 2008 Dec [cited 2017 May 1];32(12):3090-111. Available from: http://linkinghub.elsevier.com/retrieve/pii/S0098135408000756

81. Iman RL, Conover WJ. A distribution-free approach to inducing rank correlation among input variables. Commun Stat - Simul Comput [Internet]. 2007 Jun 27 [cited 2014 Nov 25];11(3):311-34. Available from: http://www.tandfonline.com/doi/abs/10.1080/03610918208812265 